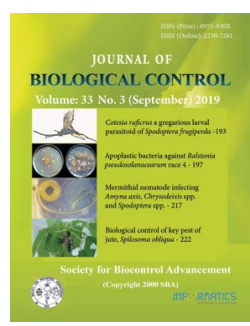

Research Article

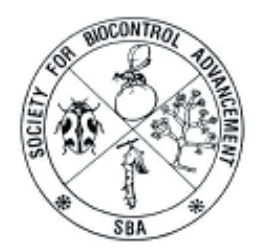

\title{
Diversity and antagonistic potential of apoplastic bacteria against Ralstonia pseudosolanacearum race 4 causing bacterial wilt of ginger
}

\author{
T. P. PRAMEELA and R. SUSEELA BHAI* \\ Division of Crop Protection, ICAR-Indian Institute of Spices Research, Marikunnu PO, Kozhikode - 673012, Kerala, India \\ *Corresponding author E-mail: rsbhai@rediffmail.com
}

\begin{abstract}
Bacterial wilt caused by Ralstonia pseudosolanacearum race 4 is a devastating disease of ginger, for which almost all control measures met with limited success. In this study, 150 bacteria isolated from the apoplastic fluid of ginger were screened for antagonism against R. pseudosolanacearum both in vitro and in planta and shortlisted six isolates which were further characterized for biocontrol and plant growth promoting traits. The promising isolates were identified as Bacillus subtilis (IISRGAB 5), B. marisflavi (IISRGAB 43), B. licheniformis (IISRGAB 107), Agrobacterium tumefaciens (IISRGAB24), Micrococcus luteus (IISRGAB 48) and Staphylococcus haemolyticus (IISRGAB 146). Green house evaluation against $R$. pseudosolanacearum, by seed priming and soil drenching showed that $B$. licheniformis strain GAP107-MTCC 12725, was able to reduce bacterial wilt incidence up to $67 \%$. Hence, this bacterium was identified as a suitable candidate for developing a potential biocide for the management of bacterial wilt in ginger.
\end{abstract}

KEYWORDS: Apoplastic Bacillus licheniformis, bacterial wilt, ginger, Ralstonia pseudosolanacearum race 4

(Article chronicle: Received: 08-06-2019; Revised: 12-08-2019; Accepted: 25-08-2019)

\section{INTRODUCTION}

Ginger (Zingiber officinale Rosc.) is one of the valuable spice crop cultivated in India and outside for the spicy green ginger and dried ginger. Bacterial wilt caused by Ralstonia pseudosolanacearum race 4 is a severe threat to ginger cultivation in all the ginger growing tracts (Kumar and Hayward, 2005). The pathogen is both soil and seed borne and the perpetuation of the disease is through seed and soil borne inoculum. Different management strategies are in practice but none of them met with satisfactory disease control. Since organic farming is gaining momentum, ecofriendly biological control measures are highly preferable to chemical control which poses serious environmental threats. Several rhizobacteria, endophytic bacteria, actinomycetes, phages etc were evaluated for bacterial wilt management in many economically important crops ((Lemessa and Zeller, 2007; Yamada et al., 2007; Ramesh et al., 2009; Barretti et al., 2012; Achari and Ramesh, 2014; Yuan et al., 2014)). In ginger, the common strategies adopted for bacterial wilt management include selection of disease free rhizomes, selection of fields with no history of bacterial wilt, seed treatment using chemicals, strict phytosanitory measures to avoid the carryover of pathogen inoculum through field workers or irrigation water and crop rotation with non- host plants (Kumar and Hayward, 2005).

Endophytes may confer resistance against pathogens, by induction of defence reactions, production of antagonistic substances or through competition for colonization of sites and nutrients (Kloepper et al., 2004). Ralstonia pseudosolanacearum being a xylem inhabitant, moving through the intercellular spaces, endophytes residing in the apoplast can be a suitable source of antagonists to explore. So, the objective of the present study was to exploit the antagonistic potential of apoplastic bacteria against $R$. pseudosolanacearum race 4 causing bacterial wilt of ginger.

\section{MATERIALS AND METHODS}

\section{Isolation of ginger apoplastic microorganisms plant material}

Ginger plants were collected from different ginger growing tracts of Kerala and Karnataka and from different germplasm accessions maintained at ICAR-Indian Institute of Spices Research experimental farm Peruvannamuzhi, 
Kozhikode, Kerala. Fresh and healthy ginger plants were collected in fresh polythene bags and sealed properly, labelled and brought to the laboratory at ICAR-IISR for further processing.

\section{Extraction of apoplastic fluid}

The collected ginger plants were thoroughly washed with tap water, the leaves and pseudostems were cut individually into bits of $7-10 \mathrm{~cm}$ length and surface sterilized by immersing in $70 \%$ ethanol in a sterile polyethylene bottle for 10 minutes and transferred to $5 \% \mathrm{H}_{2} \mathrm{O}_{2}$ for $5 \mathrm{~min}$. These were then washed four times in sterile distilled water (Asis et al., 2003). Apoplastic fluid was extracted from surface sterilized leaves and pseudostems by vacuum infiltration and centrifugation (Nouchi et al., 2012) with slight modifications. Leaf/ pseudostem bits (5-8 bits) were immersed in sterile distilled water in a glass beaker and placed in vacuum desiccator. The vacuum was applied for 15 minutes for leaves and 30 minutes for pseudostems at $40 \mathrm{kPa}$ pressure by releasing and re-applying vacuum for 5 minutes interval. After vacuum infiltration, the leaves and pseudostem bits were transferred into sterile filter paper and surface dried inside a laminar air flow cabinet. After drying, 3-4 leaves were rolled vertically and placed inside a centrifuge tube with conical bottom in such a way that the petiole is facing towards the bottom of the tube and centrifuged at $3000 \mathrm{~g}$ for 10 minutes at $4^{\circ} \mathrm{C}$ using Beckman coulter Avanti J-301centrifuge. Similarly, vacuum infiltration and centrifugation was applied for pseudostems also. After centrifugation the leaves/pseudostems were removed and the remaining fluid at the bottom was taken as the apoplastic fluid.

\section{Isolation of culturable microbes from apoplastic fluid}

The extracted apoplastic fluid was either directly plated (depending on the quantity extracted) or serially diluted up to $10^{-6}$ and $0.1 \mathrm{ml}$ was plated on to selective media, viz. Tryptic Soy Agar (TSA) for bacteria, Rose Bengal Agar (RBA) for fungi and Actinomycetes Isolation Agar (AIA) for actinomycetes. TSA and RBA plates were incubated at $28^{\circ} \mathrm{C}$ for five days at day- night intervals and AIA plates were incubated at $28^{\circ} \mathrm{C}$ for 15 to 20 days. Based on the morphological difference, bacteria were selected, purified and maintained in $40 \%$ glycerol at $-80^{\circ} \mathrm{C}$. Working stock was maintained at $-30{ }^{\circ} \mathrm{C}$.

\section{Characterization of apoplastic bacteria Morphological characterization}

The bacteria were sub-cultured on to tryptic soy agar and morphological characteristics of bacterial colonies such as colour, shape, size, elevation, surface, texture, opacity etc., were observed. Pure colonies were subjected to Gram staining and biochemical tests. Gram staining for differentiating the bacteria into gram positive or gram negative was done using standard staining procedure. The stained slides were air dried and observed under oil immersion objective of Leica DM 5000B microscope.

\section{Biochemical characterization}

The basic biochemical characterization the apoplastic bacteria were done using catalase test and carbohydrate fermentation test. It is essential for differentiating catalasepositive from catalase-negative bacteria for classification in the genus level. Catalase test was done using $3 \% \mathrm{H}_{2} \mathrm{O}_{2}$ (Clarke and Cowan, 1952). In carbohydrate fermentation test, the ability of the apoplastic bacteria to utilize different carbohydrate was tested. Nutrient broth containing appropriate sugars at a concentration of $0.5 \%$ (glucose, lactose, sucrose, mannitol and sorbitol) was used and phenol red $(0.018 \mathrm{mg}$ in $100 \mathrm{ml})$ was added as the $\mathrm{pH}$ indicator dye (MacFaddin, 2000). To the media the test bacteria were inoculated and incubated at $30^{\circ} \mathrm{C}$ for $24 \mathrm{~h}$. The change in colour of the dye from red to yellow was recorded as positive. If the colour remains same, the test bacteria could not utilize the respective sugar source and was recorded as negative.

\section{In vitro screening of apoplastic bacteria}

The 150 isolates of apoplastic bacteria extracted from ginger and maintained as glycerol stocks were retrieved in pure culture (Prameela, 2016) and tested for their antagonism to $R$. pseudosolanacearum by cross streak method (Lemos et al., 1985) using Kings' B (KB) agar medium. The plates were incubated at $28^{\circ} \mathrm{C}$ for $48 \mathrm{~h}$. After incubation, the plates were streaked with the race 4 biovar 3 virulent strain of $R$. pseudosolanacearum GRs- Mnt2 as parallel lines without touching the apoplastic bacterial line in the middle. The plates were again incubated for $48 \mathrm{~h}$. at $28^{\circ} \mathrm{C}$ and the zone of inhibition was measured. The experiment was repeated twice.

\section{In planta screening}

Potting mixture containing soil, sand and farmyard manure (3:1:1) was filled in plastic basins of $15 \times 7 \mathrm{~cm}$ and planted with three ginger rhizome bits $(\sim 10 \mathrm{~g}$ each) (varietyIISR Varada). After germination, (30 days old), the apoplstic bacterial inoculum at a concentration of $1 \times 10^{9} \mathrm{CFU} \mathrm{ml}{ }^{-1}$ was poured around the base of the plants @ $100 \mathrm{ml} \mathrm{basin}^{-1}$. After two weeks of inoculation, all the plants were challenged with $50 \mathrm{ml}$ of OD 0.1 (absorbance at $600 \mathrm{~nm}=0.1$ ) culture of $R$. pseudosolanacearum strain GRs Mnt2. A set of plants inoculated with pathogen alone served as the positive control and another set without pathogen or apoplastic bacteria served as absolute control. After inoculation, the plants were observed for typical green wilt symptoms such as downward 
drooping of leaves and wilting of pseudostem.

\section{In vitro antagonism by agar well diffusion test}

Six apoplastic bacteria after preliminary evaluation were screened for in vitro antagonism against $R$. pseudosolanacearum by agar well diffusion method (Ramesh et al., 2009) using KB agar medium. The plates were incubated at $28^{\circ} \mathrm{C}$ for 48 hours and the zone of inhibition was recorded by measuring the radius $(\mathrm{mm})$ from the outer edge of the well. The experiment was repeated twice.

\section{Biocontrol traits}

The isolates were screened for the production of siderophore on solid siderophore Chrome azurol S (CAS) blue agar plates as described by Schwyn and Neilands, 1987, production of hydrogen cyanide was checked using the method of Lorck, 1948 and acetoin production as per Cappuccino and Sherman, 2005.

\section{Plant growth promoting traits}

The growth promoting traits viz. Ammonia production by Nessler's reagent method (Cappuccino and Sherman, 1992), IAA production by Salkowsky's reagent method (Sarwar and Kremer, 1995) and Phosphate solubilization using Pikovskayas agar medium (Gaur, 1990), were tested for the selected isolates using standard procedures.

\section{Extracellular enzyme production}

Extracellular enzymes like production of $\alpha$ - amylase was tested in starch agar (Aneja, 2003), protease in Skim milk agar (HiMedia Laboratories) (Vermelho et al., 1996), lipase in tributyrin agar containing of tributyrin (Collins et al., 1995) and cellulase in Carboxymethyl Cellulose (CMC) agar plates (Apun et al., 2000) as per standard procedures.

\section{Molecular identification of promising isolates}

Genomic DNA was extracted from the six bacteria using Qiagen blood and tissue mini kit (Quagen, Germany). 100ng DNA was used for the PCR amplification of 16S rDNA using universal primers (pAF-5' AGAGTTTGATCCTGGCTCAG 3' and pHR- 5' AAGGAGGTGATCCAGCCGCA 3'). PCR amplification of was done using GoTaq PCR reagents (Promega corporation, USA) and the temperature profile include initial denaturation at $96^{\circ} \mathrm{C}$ for 9 min followed by 30 cycles of $95^{\circ} \mathrm{C}$ for $1 \mathrm{~min}, 48^{\circ} \mathrm{C}$ for $1 \mathrm{~min}, 72^{\circ} \mathrm{C}$ for $1 \mathrm{~min} 30$ $\mathrm{s}$ with a final extension of $72^{\circ} \mathrm{C}$ for $10 \mathrm{~min}$. All PCR products were electrophoresed through a $1.0 \%$ agarose gel and purified using the Gel Elution kit (Sigma Aldrich, USA). The purified PCR products were sequenced bi-directionally on an ABI PRISM Genetic Analyzer by the same PCR conditions and the same primers used for PCR amplification. The sequences were assembled in DNA baser software package (DNA
Sequence Assembler v3 (2013), Heracle BioSoft, www. DnaBaser.com) and sequences were analyzed.

\section{Pot culture evaluation of apoplastic bacteria against Ralstonia pseudosolanacearum race 4}

Pot experiment was conducted for the evaluation of six apoplastic bacteria to test their biocontrol efficacy against bacterial wilt. Besides, its colonization in the rhizosphere and apoplastic fluid of ginger plants was also studied.

\section{Seed priming and planting}

To assure the apoplastic colonization, ginger seed rhizomes were pre-primed by soaking in apoplastic bacterial suspension. Briefly, the $48 \mathrm{~h}$ grown bacterial culture was pelleted by centrifugation at $8000 \mathrm{rpm}$ for $5 \mathrm{~min}$ at $4^{\circ} \mathrm{C}$ and re-suspended in sterile distilled water so as to get an optical density of 1.0 at $600 \mathrm{~nm}$ which is equivalent to $10^{9} \mathrm{CFU} \mathrm{m}{ }^{-1}$. The ginger seed rhizomes (cv-Rejatha) were soaked in these apoplastic bacterial suspensions for about 45- $60 \mathrm{~min}$ and air dried on a blotting paper. Approximately $25 \mathrm{~g}$ pre primed ginger bit were planted in pots containing potting mixture of soil, sand and farm yard manure in a ratio $1: 1: 1$. The experiment was in CRD with 19 treatments (Table 3 ) and 3 replications with three pots/replication. The treatments were four apoplastic bacteria individually (IISRGAB 5, IISRGAB 43, IISRGAB 48 and IISRGAB 107, their combination in two, three and four, copper oxychloride $(0.25 \%)$, streptomycin sulphate (200ppm), positive control with pathogen alone and absolute control. After 45 days of planting, the plants were challenged with $R$. pseudosolanacearum GRs Mnt2 ( $\left.10^{8} \mathrm{CFU} / \mathrm{ml}\right)$. Disease incidence was recorded at specific intervals. The tiller count of each plant was recorded on the day of pathogen inoculation and the plants were observed for the typical wilting symptoms. The experiment was repeated in the successive year also.

\section{Study on soil physical properties}

$\mathrm{pH}$, electrical conductivity and dehydrogenase enzyme activity was analysed using standard protocols besides pathogen population and population of introduced bacteria. $\mathrm{pH}$ was measured using a calibrated $\mathrm{pH}$ meter (Mettler Toledo, Switzerland). Electrical conductivity was measured using Cyberscan Con II conductivity/TDS $/{ }^{\circ} \mathrm{C}$ meter (Eutech Instruments, Singapore). Dehydrogenase activity of soil was tested according to the protocol of Casida et al., 1964.

Estimation of pathogen population and introduced apoplastic bacteria from the soil

The population level of $R$. pseudosolanacearum in the soil was estimated by serial dilution plating in SMSA (Engelbrecht, 1994). Serially diluted soil samples were plated in tryptic soy agar to compare natural bacterial population with that of apoplastic bacteria treated soil. 
Colonization of bacterial population in ginger roots, rhizomes, pseudostems and leaves

To compare the colonization of introduced apoplastic bacteria in ginger roots and rhizomes, the roots and rhizomes were washed in tap water and surface sterilized with $1 \%$ sodium hypochlorite for 5 minutes and then washed in sterile distilled water. It is then immersed in $70 \%$ ethanol for $5 \mathrm{~min}$ and washed thrice in sterile distilled water. From this $0.1 \mathrm{~g}$ of the tissue was ground in phosphate buffer of $\mathrm{pH}$ 7.0. This suspension was serially diluted and plated in Tryptic Soy Agar (TSA) and TSA amended with $\mathrm{NaCl}(7 \%)$. The plates were incubated for $3-4$ days at $28^{\circ} \mathrm{C}$ and observed for the bacterial colonies. The apoplastic fluid of pseudostems and leaves was extracted by vacuum infiltration and centrifugation method (36). This apoplastic fluid was plated in TSA and TSA amended with $\mathrm{NaCl}(7 \%)$ and incubated for 3 to 5 days and observed for the presence of typical colonies.

\section{RESULTS AND DISCUSSION}

\section{Isolation of ginger apoplastic microorganisms}

When apoplastic fluid was plated in three different selective media for isolation of fungi, bacteria and actinomycetes, colonies appeared only in bacterial media. No fungal or actinomycetes colonies appeared in their respective media even after 20 days of incubation. From the bacterial medium (Tryptic Soy Agar) a total of 150 bacterial colonies differing in colony morphology were isolated, purified and maintained as glycerol stock in $40 \%$ glycerol at $-80^{\circ} \mathrm{C}$ (Fig. 1). The yield of apoplastic bacteria ranged from $3 \times 10^{1}$ to $3 \times 10^{3}$ in the pseudostems and $2 \times 10^{2}$ to $2 \times 10^{3}$ in the leaves from plants collected from different ginger growing tracts, whereas the yield ranged from $3 \times 10^{1}$ to $3 \times 10^{3}$ in and $1 \times 10^{1}$ to $9.9 \times 10^{2}$ respectively in the rhizomes and in the leaves of plants collected from different ginger germplasm accessions. It is interested to note that two of the germplasm accessions CLT-G-0139 and CLT-G-0413 did not show the presence of any culturable bacteria from apoplastic fluid on tryptic soy agar, so also, the leaves of ginger plant from Peruvannamuzhi, Kozhikode and also the germplasm accessions CLT-G-0089, CLT-G-0144， CLT-G-0187， CLT-G-0201， CLT-G-0204, CLT-G-0224, CLT-G-0249, CLT-G-0276. The isolates were named by giving the prefix IISRGAB where GAB stands for Ginger Apoplastic Bacteria and IISR stands for Indian Institute of Spices Research. They were numbered serially from 1 to 150 . The details of apoplastic bacteria isolated are given in Table 1 and Table 2.

\section{Diversity of apoplastic bacteria}

A great diversity was obtained in the population of apoplastic bacteria isolated from ginger (Supplementary fig. 1). A maximum of 15 diverse bacteria were obtained from a place called Nanminda in Kozhikode district of Kerala. A maximum of 8-7 diverse types were obtained from cultivars like Maran, Mahima Varada, Rejatha, Rio de Janeiro etc. But in the germplasm accessions maximum diversity was observed in accession number CLT-G-0171, which was originally collected from Wayanad, Kerala. But from the other germplasm accessions only 1-4 diverse isolates could be obtained.

Gram staining of these 150 isolates clearly indicated that $41.99 \%$ are of gram positive rods belonging to families Bacillaceae (38.66\%) and Lactobacillaceae (3.33\%) and $37.31 \%$ are of gram negative rods of families viz. Pseudomonadaceae (22.66\%). Enterobacteriacea (7.33\%)

Table 1. Details of apoplastic bacteria isolated from ginger fields

\begin{tabular}{|c|c|c|c|c|c|c|}
\hline Sl. No. & Place & $\begin{array}{l}\text { Latitude \& } \\
\text { Longitude }\end{array}$ & Variety & $\begin{array}{c}\text { CFU ml-1 } \\
\text { (Pseudostem) }\end{array}$ & $\begin{array}{l}\text { CFU ml-1 } \\
\text { (Leaf) }\end{array}$ & No. of Bacterial isolate \\
\hline 1 & $\begin{array}{l}\text { Peruvannamuzhi, } \\
\text { Kozhikode, Kerala }\end{array}$ & $\begin{array}{c}11^{\circ} 35^{\prime} \mathrm{N} \& 75^{\circ} \\
49^{\prime} \mathrm{E} \\
\end{array}$ & Mahima & $4.2 \times 102$ & No bacteria & $\begin{array}{l}8 \text { (IISRGAB, } 1,2,3,4,5,6,7 \\
\& 8)\end{array}$ \\
\hline 2 & $\begin{array}{l}\text { Nanmanda, Kozhikode, } \\
\text { Kerala }\end{array}$ & $\begin{array}{c}11^{\circ} 24^{\prime} \mathrm{N} \& \\
75^{\circ} 49^{\prime} \mathrm{E}\end{array}$ & Varada & $5.6 \times 102$ & $6.6 \times 102$ & 15(IISRGAB 43 to 57 ) \\
\hline 3 & $\begin{array}{l}\text { Ambalavayal, Wayanad, } \\
\text { Kerala }\end{array}$ & $\begin{array}{l}11^{\circ} 37^{\prime} \mathrm{N} \& \\
76^{\circ} 12^{\prime} \mathrm{E}\end{array}$ & Maran & $3 \times 101$ & $2.55 \times 103$ & $\begin{array}{l}5 \text { (IISRGAB58,59,60, } \\
61 \& 62)\end{array}$ \\
\hline 4 & Pulpally, Wayanad, Kerala & $\begin{array}{c}11^{\circ} 47^{\prime} \mathrm{N} \& \\
76^{\circ} 9^{\prime} \mathrm{E}\end{array}$ & Maran & $3.24 \times 103$ & $2 \times 102$ & $\begin{array}{l}7(\text { IISRGAB } 3,64,65,66, \\
67,68 \& 69)\end{array}$ \\
\hline 5 & Suntikoppa, Karnataka & $\begin{array}{l}12^{\circ} 28^{\prime} \mathrm{N} \& 75 \\
{ }^{\circ} 49^{\prime} \mathrm{E}\end{array}$ & $\begin{array}{l}\text { Riode } \\
\text { Janeiro }\end{array}$ & $7.2 \times 102$ & $1.24 \times 103$ & $\begin{array}{l}\text { 7(IISRGAB35,36,37, } \\
38,39,40,41 \& 42)\end{array}$ \\
\hline 6 & $\begin{array}{l}\text { Appangala, Kodagu, } \\
\text { Karnataka }\end{array}$ & $\begin{array}{c}12^{\circ} 26^{\prime} \mathrm{N} \& \\
75^{\circ} 45^{\prime} \mathrm{E}\end{array}$ & Mahima & $3.6 \times 102$ & $8.4 \times 102$ & $\begin{array}{l}7 \text { (IISRGAB21,22,23, } \\
24,25,26 \& 27)\end{array}$ \\
\hline 7 & $\begin{array}{l}\text { Appangala, Kodagu, } \\
\text { Karnataka }\end{array}$ & $\begin{array}{l}12^{\circ} 26^{\prime} \mathrm{N} \& \\
75^{\circ} 45^{\prime} \mathrm{E}\end{array}$ & Suravi & $2.4 \times 102$ & $3.2 \times 102$ & $\begin{array}{l}\text { 7(IISRGAB 8,29,30, 31, } \\
32,33 \& 34)\end{array}$ \\
\hline
\end{tabular}


Table 2. Details of apoplastic bacteria isolated from ginger germplasm accessions

\begin{tabular}{|c|c|c|c|c|c|c|}
\hline Sl. No. & $\begin{array}{l}\text { Ginger acces- } \\
\text { sion no }\end{array}$ & Habitat & Collection place & $\begin{array}{l}\text { CFU ml-1 (pseu- } \\
\text { dostem) }\end{array}$ & $\begin{array}{l}\text { CFU ml-1 } \\
\text { (Leaf) }\end{array}$ & $\begin{array}{l}\text { No. of bacterial isolates } \\
\text { obtained }\end{array}$ \\
\hline 1 & CLT-G-0089 & Cultivated & No data available & $1.3 \times 102$ & No bacteria & 2 (IISRGAB 9\& 10) \\
\hline 2 & CLT-G-0098 & Cultivated & Khasi Hills, Meghalaya & $2.1 \times 102$ & $4.6 \times 102$ & 2 (IISRGAB $102 \& 103$ ) \\
\hline 3 & CLT-G-0103 & Cultivated & Karbhi Anglong, Assam & $2.1 \times 102$ & $2.7 \times 102$ & $\begin{array}{l}4 \text { (IISRGAB 104, 105, } 106 \\
\& \text { 107) }\end{array}$ \\
\hline 4 & CLT-G-0127 & Cultivated & Mudigere, Karnataka & $3 \times 101$ & $7 \times 101$ & 2 (IISRGAB $70 \& 71$ ) \\
\hline 5 & CLT-G-0139 & Cultivated & No data available & No bacteria & No bacteria & No bacteria \\
\hline 6 & CLT-G-0144 & Cultivated & No data available & $1.6 \times 102$ & No bacteria & 2 (IISRGAB $11 \& 12$ ) \\
\hline 7 & CLT-G-0160 & Velliyur & Kozhikode, Kerala & $1.04 \times 103$ & $1.9 \times 102$ & \begin{tabular}{|l}
5 (IISRGAB 13, 14, 72,73 \& \\
74 )
\end{tabular} \\
\hline 8 & CLT-G-0165 & Cultivated & Wayanad, Kerala & $1.0 \times 102$ & $1 \times 101$ & 3 (IISRGAB 15, 75 \& 76) \\
\hline 9 & CLT-G-0171 & Cultivated & Wayanad, Kerala & $4.5 \times 102$ & $3.8 \times 102$ & \begin{tabular}{|l|}
6 (IISRGAB 77, \\
$78,79,80,81 \& 82)$ \\
\end{tabular} \\
\hline 10 & CLT-G-0187 & Cultivated & Assam & $1.2 \times 102$ & No bacteria & 1 (IISRGAB 15) \\
\hline 11 & CLT-G-0201 & Cultivated & $\begin{array}{l}\text { Angamali market, Eranaku- } \\
\text { lam }\end{array}$ & $3 \times 101$ & No bacteria & 1 (IISRGAB 16) \\
\hline 12 & CLT-G-0203 & Cultivated & Kottayam, Kerala & $1.7 \times 102$ & $9.9 \times 102$ & 3 (IISRGAB 83,84\&85) \\
\hline 13 & CLT-G-0204 & Cultivated & Thodupuzha, Kerala & $2.3 \times 102$ & No bacteria & 3 (IISRGAB 86,87\&88) \\
\hline 14 & CLT-G-0211 & Cultivated & $\begin{array}{l}\text { Chengannur, Alappuzha, } \\
\text { Kerala }\end{array}$ & $1.2 \times 102$ & $1.2 \times 102$ & 2 (IISRGAB $89 \& 90$ ) \\
\hline 15 & CLT-G-0219 & Cultivated & Nagerkoil, Tamil Nadu & $5 \times 101$ & $3 \times 102$ & 5 (IISRGAB 91, 92,93,94\&95) \\
\hline 16 & CLT-G-0224 & Cultivated & Sooranad, Kollam, Kerala & $9 \times 101$ & No bacteria & 1 (IISRGAB 17) \\
\hline 17 & CLT-G-0227 & Cultivated & $\begin{array}{l}\text { Angamali, Eranakulam, } \\
\text { Kerala }\end{array}$ & $1.0 \times 102$ & $1.4 \times 102$ & 3 (IISRGAB 96, $97 \&$ 98) \\
\hline 18 & CLT-G-0238 & Cultivated & Pottangi, Orissa & $3.22 \times 103$ & $7.6 \times 102$ & 2 (IISRGAB 99, $100 \& 101$ ) \\
\hline 19 & IISR-240 & wild & $\begin{array}{l}\text { Silent Valley, Palakkad, } \\
\text { Kerala }\end{array}$ & $1.3 \times 102$ & $1.7 \times 102$ & 2 (IISRGAB $117 \& 118$ ) \\
\hline 20 & IISR-246 & wild & Sabarimala, Kerala & $2 \times 101$ & $1.6 \times \times 102$ & $\begin{array}{l}4 \text { (IISRGAB 126,127,128 \& } \\
129 \text { ) }\end{array}$ \\
\hline 21 & CLT-G-0249 & Cultivated & Jorhat, Assam & $1.1 \times 102$ & No bacteria & 1 (IISRGAB 18) \\
\hline 22 & CLT-G-0253 & Cultivated & Shillong, Meghalaya & $1.5 \times 102$ & $1.9 \times 102$ & 1 (IISRGAB 119) \\
\hline 23 & CLT-G-0254 & Cultivated & Howrah, West Bengal & $2.2 \times 102$ & $3.5 \times 102$ & 1 (IISRGAB 120) \\
\hline 24 & CLT-G-0255 & Cultivated & Agarthala, Tripura & $3.2 \times 102$ & $4.6 \times 102$ & $\begin{array}{l}4 \text { (IISRGAB 130, 131, } 132 \\
\& 133 \text { ) }\end{array}$ \\
\hline 25 & CLT-G-0261 & Cultivated & $\begin{array}{l}\text { ICAR Complex, Shillong, } \\
\text { Meghalaya }\end{array}$ & $1.8 \times 102$ & $1.2 \times 102$ & 1 (IISRGAB 121) \\
\hline 26 & CLT-G-0276 & Cultivated & Agarthala, Tripura & $3 \times 101$ & No bacteria & 2 (IISRGAB $19 \& 20$ ) \\
\hline 27 & CLT-G-0296 & Cultivated & Pathanamthitta, Kerala & $1.20 \times 103$ & $2.9 \times 102$ & 2 (IISRGAB $108 \&$ 109) \\
\hline 28 & CLT-G-0413 & Cultivated & Visakhapatnam & No bacteria & No bacteria & No colonies \\
\hline 29 & CLT-G-0428 & Cultivated & Jamaica & $2.0 \times 102$ & $1.8 \times 102$ & $\begin{array}{l}4 \text { (IISRGAB 110,111,112 \& } \\
113 \text { ) }\end{array}$ \\
\hline 30 & CLT-G-0441 & Cultivated & Jamaica & $6.4 \times 102$ & $2.3 \times 102$ & 1 (IISRGAB 122) \\
\hline
\end{tabular}




\begin{tabular}{|l|l|l|l|l|l|l|}
\hline 31 & CLT-G-0442 & Cultivated & Jamaica & $3.12 \times 103$ & $2 \times 102$ & 3 (IISRGAB 114,115 \& 116) \\
\hline 32 & CLT-G-0443 & Cultivated & Jamaica & $2.3 \times 102$ & $4.2 \times 102$ & 2 (IISRGAB 123 \& 124) \\
\hline 33 & CLT-G-0449 & Cultivated & Siddapur, Karnataka & $1.8 \times 102$ & $3.4 \times 102$ & 2 (IISRGAB 134 \& 135) \\
\hline 34 & CLT-G-0464 & Cultivated & Hajipur, Bihar & $5 \times 101$ & $2.4 \times 102$ & 2 (IISRGAB 136 \& 137) \\
\hline 35 & CLT-G-0465 & Cultivated & Patna, Bihar & $2.52 \times 102$ & $3.4 \times 102$ & 1 (IISRGAB 125) \\
\hline 36 & CLT-G-0469 & Cultivated & Wadakkanchery, Palakkad, Kerala & $2.8 \times 102$ & $1.3 \times 102$ & 4 (IISRGAB 138,139,140 \& 141) \\
\hline 37 & CLT-G-0485 & Cultivated & Parakkode, Kollam, Kerala & $3.0 \times 102$ & $1.2 \times 102$ & 4 (IISRGAB 142,143,144 \& 145) \\
\hline 38 & CLT-G-0519 & Cultivated & Munnar, Idukki, Kerala & $6.2 \times 102$ & $1.8 \times 102$ & 5 (IISRGAB 146,147,148,149\& 150) \\
\hline
\end{tabular}
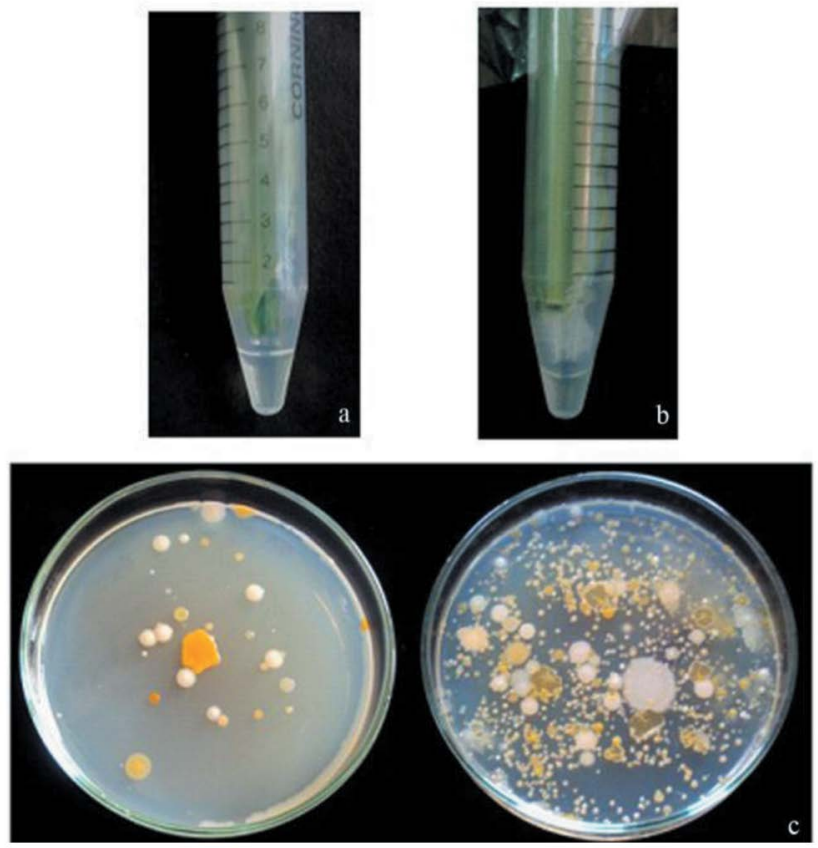

Fig. 1. (a) Apoplastic fluid extracted from ginger leaf. (b) apoplastioc fluid extracted from ginger pseudostem. (c) Bacterial colonies on tryptic soy agar.

Rhizobiaceae (2.66\%), Aeromonadaceae (3.33\%) and Moraxellaceae (3.33\%) (Table 4; Supplementary Fig. 2).

\section{Biochemical diversity}

More than $88.67 \%$ of ginger apoplastic bacteria produced the enzyme catalase which is indicated by the bubble formation immediately on adding $\mathrm{H}_{2} \mathrm{O}_{2}$. Based on the carbohydrate utilization pattern, the 150 isolates form 22 groups, out of which $5.33 \%$ can utilize all five tested carbohydrates while $26 \%$ cannot utilize any one of the five carbohydrates tested. $22.67 \%$ can use glucose, sucrose and mannitol and $14 \%$ can use glucose and sucrose. None of the bacteria utilize mannitol alone, where as it was found that seven isolates can utilize glucose alone, five isolates sucrose alone and two isolates sorbitol alone (Table 3).

\section{In vitro and in planta Screening}

Among the 150 bacteria isolated from apoplastic
Table 3. Carbohydrate utilization of apoplastic bacteria

\begin{tabular}{|c|c|c|c|}
\hline $\begin{array}{l}\text { Sl. } \\
\text { No. }\end{array}$ & $\begin{array}{l}\text { Sugar utiliza- } \\
\text { tion pattern }\end{array}$ & $\begin{array}{l}\text { Apoplastic bacterial } \\
\text { isolates (IISR GAB) }\end{array}$ & $\begin{array}{c}\text { No. of } \\
\text { bacteria vs. } \\
\text { Percentage }\end{array}$ \\
\hline 1 & All five sugars & $26,27,33,37.39,40,41,44$ & $8(5.33 \%)$ \\
\hline 2 & No sugars & $\begin{array}{l}1,2,8,9,10.11,12,24,31,32, \\
51,60,62,65,66,67,69,70,7 \\
1,72,73,74,75,76,77,78,79 \\
80,81,82,86,92,93,94,95, \\
105,108.132,149\end{array}$ & $39(26 \%)$ \\
\hline 3 & Glucose alone & $54,56,85,88,89,100,107$ & $7(4.67 \%)$ \\
\hline 4 & Sucrose alone & $47,64,87,137,138$ & $5(3.33 \%)$ \\
\hline 5 & Lactose alone & $6,7,14$ & $3(2.0 \%)$ \\
\hline 6 & Mannitol alone & No bacteria & - \\
\hline 7 & Sorbitol alone & 16,63 & $2(1.33 \%)$ \\
\hline 8 & $\begin{array}{l}\text { Glucose \& } \\
\text { sucrose }\end{array}$ & $\begin{array}{l}29,57,59,90,97,101,109,1 \\
11,112,116,117,119,121 \\
127,128,133,140,141,142 \\
, 146,148\end{array}$ & $21(14.0 \%)$ \\
\hline 9 & $\begin{array}{l}\text { Glucose \& } \\
\text { lactose }\end{array}$ & 5,15 & $2(1.33 \%)$ \\
\hline 10 & $\begin{array}{l}\text { Glucose\& man- } \\
\text { nitol }\end{array}$ & $104,123,124,125,131$ & $5(3.33 \%)$ \\
\hline 11 & \begin{tabular}{|l} 
Glucose \& \\
sorbitol
\end{tabular} & $46,50,68$ & $3(2.0 \%)$ \\
\hline 12 & $\begin{array}{l}\text { Glucose, } \\
\text { Sucrose \& } \\
\text { mannitol }\end{array}$ & $\begin{array}{l}4,23,28,30,42,43,45,48,52 \\
, 53,55,58,84,91,96,99,102 \\
, 103,106,110,113,114,115 \\
, 118,120,129,130,134,135 \\
, 136,139,143,144,147\end{array}$ & $34(22.67 \%)$ \\
\hline 13 & \begin{tabular}{|l} 
Glucose, \\
sucrose \& \\
sorbitol
\end{tabular} & 126 & $1(0.67 \%)$ \\
\hline 14 & $\begin{array}{l}\text { Sucrose \& } \\
\text { lactose }\end{array}$ & 13,17 & $2(1.33 \%)$ \\
\hline 15 & $\begin{array}{l}\text { Sucrose \& } \\
\text { mannitol }\end{array}$ & 61,145 & $2(1.33 \%)$ \\
\hline 16 & $\begin{array}{l}\text { Sucrose, } \\
\text { lactose, } \\
\text { mannitol, } \\
\text { sorbitol }\end{array}$ & $3,19,36$ & $3(2.0 \%)$ \\
\hline
\end{tabular}




\begin{tabular}{|c|l|l|l|}
\hline 17 & $\begin{array}{l}\text { Glucose, } \\
\text { sucrose, lactose } \\
\& \text { mannitol }\end{array}$ & $25,49,83,98$ & $4(2.67 \%)$ \\
\hline 18 & $\begin{array}{l}\text { Glucose, } \\
\text { sucrose, lactose } \\
\text { \& sorbitol }\end{array}$ & 20 & $1(0.67 \%)$ \\
\hline 19 & $\begin{array}{l}\text { Glucose, } \\
\text { lactose, } \\
\text { mannitol \& } \\
\text { sorbitol }\end{array}$ & 34,35 & $2(1.33 \%)$ \\
\hline 20 & $\begin{array}{l}\text { Glucose, } \\
\text { sucrose, } \\
\text { mannitol \& } \\
\text { sorbitol }\end{array}$ & 122,150 & $2(1.33 \%)$ \\
\hline 21 & $\begin{array}{l}\text { Lactose, } \\
\text { Mannitol, } \\
\text { sorbitol }\end{array}$ & 18 & $1(0.67 \%)$ \\
\hline 22 & $\begin{array}{l}\text { Sucrose, } \\
\text { mannitol, } \\
\text { sorbitol }\end{array}$ & 38 & $1(0.67 \%)$ \\
\hline
\end{tabular}

fluid and tested, only three bacteria showed inhibition to $R$. pseudosolanacearum. The inhibition zone ranged from 2 to $10 \mathrm{~mm}$. The highest inhibition was shown by IISRGAB 5 (10mm) followed by IISRGAB 146 (5mm) (Fig. 2).

All the 150 bacteria were also tested inplanta for disease

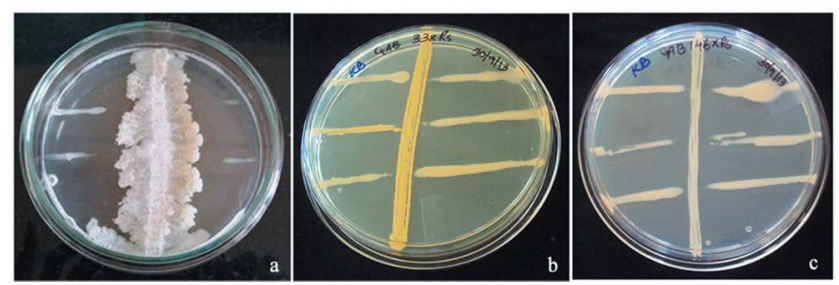

Fig. 2. Bacterial isolates showing antagonism by in vitro cross streak method (a) IISRGAB 5. (b) IISRGAB 33. (c) IISRGAB 146.

suppression. In in planta screening, infection was observed as typical bacterial wilt symptom from $10^{\text {th }}$ day onwards after inoculation. The wilting percentage ranged from $0-100 \%$ (Supplementary Table 1). The time taken for infection varied from 10-30 days. All the isolates except IISRGAB 24, IISRGAB 48 and IISRGAB 107 showed more than 75\% wilting/infection within 30 days of inoculation. One isolate IISRGAB84 showed infection within 10-15 DAI. Sixty-three isolates $(42 \%)$ showed infection in 16-30 days and three isolates showed $\geq 50 \%$ infection in 30 days which include IISRGAB 43 (20\%), IISRGAB 5 (40\%) and IISRGAB 146 (50\%). But three isolates viz. (IISRGAB 24, IISRGAB 48 and IISRGAB 107) did not took infection/wilting till the end of the experiment (Fig. 3) when compared to positive control where total collapse of plant was observed within 10 days of inoculation. The isolates that showed in vitro antagonistic effect is found ineffective under in planta evaluation, indicating that in vitro evaluation alone is insufficient to test the antagonistic ability of the organisms against soil borne pathogens.
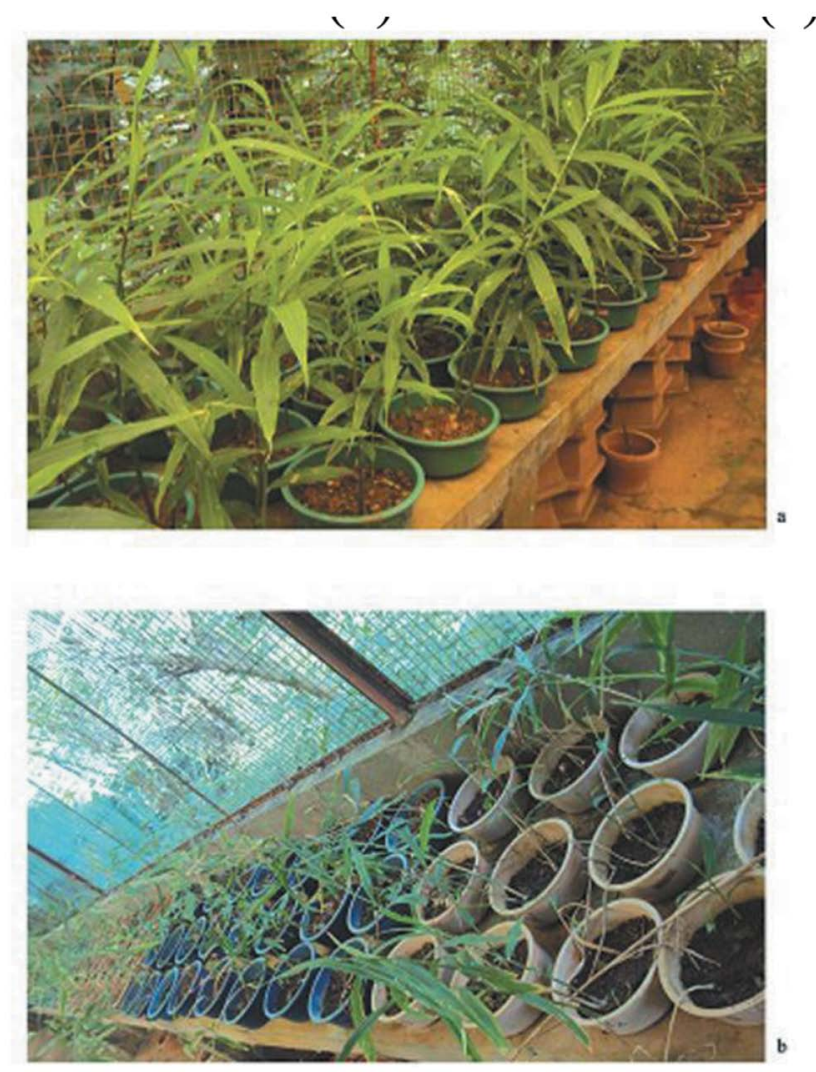

Fig. 3. In planta evaluation of apoplastic bacteria a Ginger plants before Ralstonia pseudosolanacearum inoculation b Survived plants with potential bacterial isolates.

\section{Characterization of apoplastic bacteria for potential traits}

The isolates that showed in vitro antagonistic effect as well as that showed in planta biocontrol potential were characterized for biocontrol traits. In vitro antibiosis by agar well diffusion method clearly showed the inhibition of $R$. pseudosolanacearum by three isolates viz. IISRGAB 5 , IISRGAB 43 and IISRGAB 146 (Table 5 and Supplementary Fig. 3a). The size of inhibition zone ranged between 3.5- 4.5 $\mathrm{mm}$. However, three isolates viz. IISRGAB 24, IISRGAB 48 and IISRGAB 107 did not show any inhibition.

Among the six isolates IISRGAB 5 was found to be the highest producer of siderophore followed by IISRGAB 24, IISRGAB 48 and IISRGAB 107 based on the radius of the halo formed around the colony, however, none of the short listed isolates produced $\mathrm{HCN}$. Acetoin production by glucose 
metabolism was noticed only in IISRGAB 5 and IISRGAB 107 (Table 5 and Supplementary Fig. $3 \mathrm{~b}$ and c).

All the six isolates are found producing ammonia as well as IAA. The IAA production ranged from 5.37 to $11.83 \mu \mathrm{g} \mathrm{ml}$ 1. IISRGAB 5 and IISRGAB 48 were found to be producing more IAA in comparison with other four bacteria. IISR GAB 5, IISR GAB 24, IISR GAB 107 and IISR GAB 146 could solubilise insoluble phosphate ((Table 5 and Supplementary Fig.4a, $b$ and c).

\section{Extracellular enzyme production}

Among the six isolates five (IISRGAB 5, IISR GAB 24, IISR GAB 48, IISR GAB 107, IISR GAB 146) could synthesize $\alpha$-amylase as well as cellulase. But only three isolates (IISRGAB 5, 48, 107) could produce protease (Table 5 ) while none of them could synthesize lipases.

\section{Identification of promising apoplastic bacteria}

By 16SrDNA sequencing, 1500 bp amplicons was obtained for all the six isolates (Supplementary Fig. 5). The sequences were assembled and compared with sequences of NCBI by Blastn (http://www.ncbi.nlm.nih.gov/BLAST). IISRGAB 5 showed 99\% similarity towards both Bacillus subtilis and B. amyloliquefaciens and IISRGAB 107 showed 99\% similarity towards B. licheniformis and B. sonorensis. Based on the salt tolerance test the identity of IISRGAB 5 was confirmed as B. subtilis. Similarly, in tryptic soy broth with $\mathrm{NaCl}$ concentrations from $1 \%$ to $10 \%$, turbidity was observed in all concentrations within $24 \mathrm{~h}$. of incubation confirming the identity of IISRGAB 107 as B. licheniformis. IISRGAB 43 was identified as B. marisflavi, IISRGAB 24 as Agrobacterium tumefaciens, IISRGAB 48 as Micrococcus luteus and IISRGAB 146 as Staphylococcus haemolyticus. The identity and GenBank accession numbers are given in Table 6.

\section{Pot culture evaluation}

There was significant reduction in bacterial wilt with apoplastic bacterial treatment, individually and in combination, when compared with pathogen control as well as chemical control. After 10 days of pathogen inoculation, 33-59\% disease reduction was observed with apoplastic bacteria over pathogen control while it was only $12.28 \%$ and $21.39 \%$ respectively with streptomycin sulphate and copper oxychloride, the recommended chemicals against bacterial wilt. After 20 days of pathogen inoculation there was significant difference in the disease incidence by different treatments and the disease reduction over control by different apoplastic bacteria showed wide difference ranging from 9 to $79 \%$. The treatments T15 (IISRGAB5+ IISRGAB 43+ IISRGAB 48+ IISRGAB 107) and T4 (IISRGAB 107) showed a disease reduction of $78.82 \%$ and $72.1 \%$ respectively over pathogen control and were at par with absolute control (79.94\%). The same trend was noticed even after 30 days of inoculation. But the situation was changed after 30 days where most of the apoplastic bacterial treatments, infection was found gradually increased and reached the level as in pathogen control. After 40 dai, only IISRGAB 107 treated plants showed significant reduction $(66.42 \%)$ in disease over control (Fig. 4). The periodical disease incidence is given

Table 4. Diversity of bacterial families in apoplastic fluid of ginger

\begin{tabular}{|c|c|c|c|}
\hline Bacteria & Family & Population $(\%)$ & Isolates \\
\hline \multirow[t]{2}{*}{ Gram positive rods } & Bacilacae & 38.66 & $\begin{array}{l}\text { IISRGAB 4, 5, 7, 9, 12, 14, 31, 32, 37, 43, 44, 49, 52, 53, 60, 61, 68, } \\
69,72,73,74,76,79,80,82,89,90,92,94,98,100,101,102,103, \\
104,106,107,109,111,116,117,118,123,124,127,130,131,132, \\
133,134,135,136,138,139,140,145,147,148\end{array}$ \\
\hline & Lactobacilaceae & 3.33 & IISRGAB $15,18,19,21,25$ \\
\hline \multirow{5}{*}{ Gram negative rods } & Pseudomonadaceae & 22.66 & $\begin{array}{l}\text { IISRGAB } 10,16,29,38,45,50,56,57,67,70,71,75,77,78,81, \\
95,96,97,99,105,115,119,121,122,125,126,128,129,137,141, \\
142,143,149,150\end{array}$ \\
\hline & Eterobacteriaceae & 7.33 & IISRGAB 6,13, 22, 36, 42, 40, 51, 108, 110, 113, 120 \\
\hline & Rhizobiaceae & 2.66 & IISRGAB 1, 2, 24, 91 \\
\hline & Aeromonadaceae & 3.33 & IISRGAB 23, 30, 84, 86, 87 \\
\hline & Moraxellaceae & 3.33 & IISR GAB 34, 35, 39, 93, 112 \\
\hline \multirow{2}{*}{ Gram positive cocci } & Staphylococcaceae & 10.0 & IISRGAB 3, 8, 20, 28, 55, 58, 62, 63, 64, 66, 83, 88, 114, 144, 146 \\
\hline & Micrococcaceae & 6.0 & $26,33,46,47,48,54,59,65,85$ \\
\hline Gram negative cocci & Unknown & 2.66 & IISRGAB 11, 17, 27, 41 \\
\hline
\end{tabular}


Table 5. Characterization of shortlisted isolates for biocontrol and growth promoting traits

\begin{tabular}{|c|c|c|c|c|c|c|c|c|c|c|c|}
\hline Isolate & $\begin{array}{l}\text { Inhibition } \\
\text { zone by } \\
\text { Agar gel } \\
\text { diffusion } \\
(\mathrm{mm})\end{array}$ & $\begin{array}{l}\text { Produc } \\
\text { tion of } \\
\text { Sidero } \\
\text { phore }\end{array}$ & $\begin{array}{l}\text { Produ } \\
\text { ction } \\
\text { of } \\
\text { HCN }\end{array}$ & $\begin{array}{l}\text { Produ } \\
\text { ction of } \\
\text { Acetoin }\end{array}$ & $\begin{array}{l}\text { Produc } \\
\text { tion of } \\
\text { Amm } \\
\text { onia }\end{array}$ & $\begin{array}{l}\text { Produ } \\
\text { ction } \\
\text { of } \\
\text { IAA } \\
(\mu \mathrm{g} \\
\text { ml-1) }\end{array}$ & $\begin{array}{l}\text { Phosph } \\
\text { ate solub } \\
\text { ilization }\end{array}$ & $\begin{array}{l}\text { Produ } \\
\text { ction } \\
\text { of Amy } \\
\text { lase }\end{array}$ & $\begin{array}{l}\text { Produ } \\
\text { ction } \\
\text { of Pro } \\
\text { tease }\end{array}$ & $\begin{array}{l}\text { Produ } \\
\text { ction } \\
\text { of Cell } \\
\text { ulase }\end{array}$ & $\begin{array}{l}\text { Produc } \\
\text { tion of } \\
\text { Lipase }\end{array}$ \\
\hline $\begin{array}{l}\text { IISR } \\
\text { GAB } 5\end{array}$ & 4 & + & - & + & + & 11.12 & + & + & + & + & - \\
\hline $\begin{array}{l}\text { IISR } \\
\text { GAB } \\
24\end{array}$ & 0 & + & - & - & + & 6.54 & + & + & - & + & - \\
\hline $\begin{array}{l}\text { IISR } \\
\text { GAB } \\
43\end{array}$ & 3.5 & - & - & - & + & 5.37 & - & - & - & - & - \\
\hline $\begin{array}{l}\text { IISR } \\
\text { GAB } \\
48\end{array}$ & 0 & + & - & - & + & 11.83 & - & + & + & + & - \\
\hline $\begin{array}{l}\text { IISR } \\
\text { GAB } \\
107\end{array}$ & 0 & + & - & + & + & 5.45 & + & + & + & + & - \\
\hline $\begin{array}{l}\text { IISR } \\
\text { GAB } \\
146\end{array}$ & 4.5 & - & - & - & + & 6.05 & + & + & - & + & - \\
\hline
\end{tabular}

+ Denotes presence of trait

- Denotes absence of trait

Table 6. Identification of shortlisted apoplastic bacteria by $16 \mathrm{~S}$ rDNA sequencing

\begin{tabular}{|c|l|l|l|}
\hline $\begin{array}{c}\text { Sl. } \\
\text { No }\end{array}$ & \multicolumn{1}{|c|}{ Isolate name } & \multicolumn{1}{|c|}{ Identification } & $\begin{array}{c}\text { GenBank } \\
\text { Acc. }\end{array}$ \\
\hline 1 & IISR GAB 5 & Bacillus subtilis & KU196772 \\
\hline 2 & IISR GAB 24 & $\begin{array}{l}\text { Agrobacterium } \\
\text { tumefaciens }\end{array}$ & KU196773 \\
\hline 3 & IISR GAB 43 & Bacillus marisflavi & KU258013 \\
\hline 4 & IISR GAB 48 & Micrococcus luteus & KU258014 \\
\hline 5 & IISR GAB 107 & Bacillus licheniformis & KU258015 \\
\hline 6 & IISR GAB 146 & $\begin{array}{l}\text { Staphylococcus } \\
\text { haemolyticus }\end{array}$ & KU258016 \\
\hline
\end{tabular}

in table 7 and Fig. 5. During harvest after eight months, the average yield obtained per pot with IISR GAB 107 treated plants was $161.74 \mathrm{~g}$, compared to absolute control where the average yield per pot was $179.5 \mathrm{~g}$. No yield was obtained from any other treatments. The result indicated the potential of IISR GAB 107 as an antagonist to $R$. pseudosolanacearum.

Soil parameters and population of pathogen and antagonistic bacteria in rhizosphere soil.

Different soil parameters like $\mathrm{pH}$, Electrical Conductivity
(EC) and dehydrogenase activity of the IISRGAB 107 treated soil were studied in comparison with absolute control and pathogen control (Table 4). Dehydrogenase activity, which is an indicator of soil microbial activity, was found to be more in IISRGAB 107 treated soil. There is considerable reduction in the population of $R$. pseudosolanacearum in the soil treated with IISRGAB 107 i.e., $1.2 \times 10^{3} \mathrm{CFU}$ $\mathrm{g}^{-1}$ (which is below the infection level) when compared with the pathogen control where the highest population of pathogen was present i.e. $2 \times 10^{9} \mathrm{CFU} \mathrm{g}^{-1}$. In uninoculated control, no $R$. pseudosolanacearum could be detected. Similarly, rhizosphere bacterial population was found to be more in the case of soil treated with IISRGAB 107 when compared with absolute control and pathogen control. In $R$. pseudosolanacearum treated soil there is significant reduction in the other soil bacterial population (Table 8).

\section{Comparison of endophytic population of ginger roots, rhizomes, pseudostems and leaves}

There was considerable difference in the population and diversity of bacteria in the plants treated with IISRGAB107 when compared to control. In general endophytic bacterial colonization was found higher in ginger roots in both control and IISRGAB 107 treatment, but when TSA amended with $\mathrm{NaCl}$ was used there was a 10 fold increase in the bacterial population in IISRGAB 107 treatment (T4) in roots and 100 
Table 7. Effect of selected apoplastic bacteria and their consortia in bacterial wilt management (in planta effect)

\begin{tabular}{|c|c|c|c|c|}
\hline \multirow{2}{*}{ Treatments } & \multicolumn{4}{|c|}{ Disease incidence $(\%)$} \\
\hline & 10dai & 20dai & 30dai & 40dai \\
\hline T1 IISRGAB 5 & $\begin{array}{l}19.00 \\
(9.58)\end{array}$ & $\begin{array}{l}64.21^{\mathrm{ABC}} \\
(79.89)\end{array}$ & $\begin{array}{l}62.41^{\mathrm{ABCD}} \\
(83.33)\end{array}$ & $\begin{array}{l}66.73^{A} \\
(83.33)\end{array}$ \\
\hline T2 IISRGAB 43 & $\begin{array}{l}17.77 \\
(14.58)\end{array}$ & $\begin{array}{l}45.82^{\mathrm{BCDE}} \\
(51.40)\end{array}$ & $\begin{array}{l}47.82^{\mathrm{DEF}} \\
(75.22)\end{array}$ & $\begin{array}{l}77.00^{\mathrm{A}} \\
(100.00)\end{array}$ \\
\hline T3 IISRGAB 48 & $\begin{array}{l}16.97 \\
(6.57) \\
\end{array}$ & $\begin{array}{l}49.00^{\mathrm{AB}} \\
\mathrm{CDE}(54.43) \\
\end{array}$ & \begin{tabular}{|l}
$54.74^{\mathrm{BCDE}}$ \\
$(64.01)$
\end{tabular} & \begin{tabular}{|l|}
$65.74^{\mathrm{A}}$ \\
$(82.51)$ \\
\end{tabular} \\
\hline $\begin{array}{l}\text { T4 IISRGAB } \\
107\end{array}$ & $\begin{array}{l}15.12 \\
(11.69)\end{array}$ & $\begin{array}{l}21.14^{\mathrm{EF}} \\
(11.69)\end{array}$ & $\begin{array}{l}30.39^{\mathrm{FG}} \\
(26.77)\end{array}$ & $\begin{array}{l}26.28^{\mathrm{B}} \\
(19.40)\end{array}$ \\
\hline $\begin{array}{l}\text { T5 IISRGAB } \\
5+43\end{array}$ & \begin{tabular}{|l}
22.74 \\
$(18.33)$
\end{tabular} & $\begin{array}{l}66.67^{\mathrm{AB}} \\
(88.89)\end{array}$ & $\begin{array}{l}66.67^{\mathrm{ABCD}} \\
(88.89)\end{array}$ & $\begin{array}{l}69.10^{\mathrm{A}} \\
(88.89)\end{array}$ \\
\hline $\begin{array}{l}\text { T6 IISRGAB } \\
5+48\end{array}$ & $\begin{array}{l}23.12 \\
(17.57)\end{array}$ & $\begin{array}{l}52.48^{\mathrm{ABCD}} \\
(79.37)\end{array}$ & $\begin{array}{l}53.91^{\mathrm{CDE}} \\
(77.78)\end{array}$ & $\begin{array}{l}68.83^{A} \\
(79.37)\end{array}$ \\
\hline $\begin{array}{l}\text { T7 IISRGAB } \\
5+107\end{array}$ & \begin{tabular}{|l}
21.13 \\
$(13.66)$
\end{tabular} & $\begin{array}{l}59.75^{\mathrm{ABCD}} \\
(76.67)\end{array}$ & $\begin{array}{l}68.78^{\mathrm{ABCD}} \\
(81.67)\end{array}$ & $\begin{array}{l}71.42^{\mathrm{A}} \\
(86.67)\end{array}$ \\
\hline $\begin{array}{l}\text { T8 IISRGAB } \\
43+48 \\
\end{array}$ & \begin{tabular}{|l|}
17.58 \\
$(9.92)$ \\
\end{tabular} & \begin{tabular}{|l|}
$41.40^{\mathrm{BC}}$ \\
$\mathrm{DEF}(45.91)$ \\
\end{tabular} & \begin{tabular}{|l|}
$\begin{array}{l}38.91^{\mathrm{EFG}} \\
(40.45)\end{array}$ \\
\end{tabular} & \begin{tabular}{|l|}
$71.69^{\mathrm{A}}$ \\
$(86.11)$ \\
\end{tabular} \\
\hline $\begin{array}{l}\text { T9 IISRGAB } \\
43+107\end{array}$ & $\begin{array}{l}45.65 \\
(45.40) \\
\end{array}$ & $\begin{array}{l}66.40^{\mathrm{AB}} \\
(72.22) \\
\end{array}$ & $\begin{array}{l}79.13^{\mathrm{A}} \\
(100.00) \\
\end{array}$ & $\begin{array}{l}79.13^{\mathrm{A}} \\
(100.00) \\
\end{array}$ \\
\hline $\begin{array}{l}\text { T10 IISRGAB } \\
48+107\end{array}$ & $\begin{array}{l}35.77 \\
(35.15) \\
\end{array}$ & $\begin{array}{l}50.67^{\mathrm{ABCD}} \\
(51.85) \\
\end{array}$ & $\begin{array}{l}53.17^{\mathrm{DE}} \mathrm{F} \\
(100.00)\end{array}$ & $\begin{array}{l}76.96^{\mathrm{A}} \\
(100.00) \\
\end{array}$ \\
\hline $\begin{array}{l}\text { T11 IISRGAB } \\
5+43+48\end{array}$ & $\begin{array}{l}22.61 \\
(17.78)\end{array}$ & $\begin{array}{l}56.97^{\mathrm{ABCD}} \\
(83.49)\end{array}$ & $\begin{array}{l}62.71^{\mathrm{ABCD}} \\
(100.00)\end{array}$ & $\begin{array}{l}77.64^{\mathrm{A}} \\
(100.00)\end{array}$ \\
\hline $\begin{array}{l}\text { T12 IISRGAB } \\
5+48+107\end{array}$ & $\begin{array}{l}20.03 \\
(19.80) \\
\end{array}$ & $\begin{array}{l}68.88^{\mathrm{AB}} \\
(83.33) \\
\end{array}$ & $\begin{array}{l}78.24^{\mathrm{A}} \\
(100.00) \\
\end{array}$ & $\begin{array}{l}78.24^{\mathrm{A}} \\
(100.00) \\
\end{array}$ \\
\hline $\begin{array}{l}\text { T13 IISRGAB } \\
43+48+107\end{array}$ & $\begin{array}{l}41.33 \\
(40.51)\end{array}$ & $\begin{array}{l}65.93^{\mathrm{AB}} \\
(71.93)\end{array}$ & $\begin{array}{l}78.81^{\mathrm{A}} \\
(100.00)\end{array}$ & $\begin{array}{l}74.78^{\mathrm{A}} \\
(100.00)\end{array}$ \\
\hline $\begin{array}{l}\text { T14 IISRGAB } \\
5+43+107\end{array}$ & $\begin{array}{l}23.35 \\
(20.32)\end{array}$ & $\begin{array}{l}36.53^{\mathrm{CDEF}} \\
(38.10)\end{array}$ & $\begin{array}{l}77.60^{\mathrm{AB}} \\
(100.00)\end{array}$ & $\begin{array}{l}77.60^{\mathrm{A}} \\
(100.00)\end{array}$ \\
\hline $\begin{array}{l}\text { T15 IISRGAB } \\
5+43+48+107 \\
\end{array}$ & $\begin{array}{l}16.05 \\
(8.33)\end{array}$ & $\begin{array}{l}16.05^{\mathrm{F}} \\
(8.33)\end{array}$ & $\begin{array}{l}62.01^{\mathrm{AB}} \\
\mathrm{CDE}(80.00)\end{array}$ & \begin{tabular}{|l|}
$76.91^{\mathrm{A}}$ \\
$(97.10)$
\end{tabular} \\
\hline $\begin{array}{l}\text { T16 Copper- } \\
\text { oxy chloride } \\
(0.25 \%) \\
\end{array}$ & $\begin{array}{l}27.71 \\
(21.73)\end{array}$ & $\begin{array}{l}68.88^{\mathrm{AB}} \\
(88.52)\end{array}$ & $\begin{array}{l}76.70^{\mathrm{ABC}} \\
(97.43)\end{array}$ & $\begin{array}{l}76.30^{\mathrm{A}} \\
(95.24)\end{array}$ \\
\hline $\begin{array}{l}\text { T17 Strepto } \\
\text { mycin sulphate } \\
(200 \text { ppm })\end{array}$ & $\begin{array}{l}30.92 \\
(27.95)\end{array}$ & $\begin{array}{l}30.92^{\mathrm{DEF}} \\
(27.95)\end{array}$ & $\begin{array}{l}77.71^{\mathrm{AB}} \\
(100.00)\end{array}$ & $\begin{array}{l}77.71^{\mathrm{A}} \\
(100.00)\end{array}$ \\
\hline $\begin{array}{l}\text { T18 Pathogen } \\
\text { control }\end{array}$ & \begin{tabular}{|l}
35.25 \\
$(34.45)$ \\
\end{tabular} & $\begin{array}{l}75.78^{\mathrm{A}} \\
(93.97) \\
\end{array}$ & $\begin{array}{l}67.37^{\mathrm{ABCD}} \\
(100.00) \\
\end{array}$ & $\begin{array}{l}78.27^{\mathrm{A}} \\
(100.00) \\
\end{array}$ \\
\hline $\begin{array}{l}\text { T19 Absolute } \\
\text { control }\end{array}$ & $\begin{array}{l}13.17 \\
(0.00) \\
\end{array}$ & $\begin{array}{l}15.20^{\mathrm{F}} \\
(0.00)\end{array}$ & $\begin{array}{l}15.81^{\mathrm{G}} \\
(0.00)\end{array}$ & $\begin{array}{l}18.24^{\mathrm{B}} \\
(0.00)\end{array}$ \\
\hline General Mean & 24.49 & 50.14 & 60.68 & 68.87 \\
\hline CV $(\%)$ & 55.13 & 35.15 & 23.38 & 12.71 \\
\hline SE (d) & 11.022 & 14.391 & 11.585 & 7.145 \\
\hline LSD at $5 \%$ & NS** & 29.134 & 23.452 & 14.465 \\
\hline
\end{tabular}

LSD at $5 \%$ denotes the Least Significant Difference at $\mathrm{P} \leq 0.05$

* Figures in parenthesis is original value

** NS denotes non-significant fold increase in rhizomes when compared to control (Table 8) that showed the endophytic colonization of introduced antagonist.

Since the inoculated antagonist is inhabitant of intercellular spaces (apoplast), the apoplastic colonization was also tested in the leaves and pseudostems of IISRGAB 107 treated plants i.e., when the apoplastic fluid from the pseudostem and leaf were plated in TSA and also in TSA amended with $7 \% \mathrm{NaCl}$, a higher number of bacteria were found in the treated plant tissues. The amount of apoplastic bacterial population in leaf and pseudostems of the uninoculated plant (control) remains the same. But there was a 10 fold increase in the population of apoplastic bacteria in the pseudostems and leaves of IISRGAB 107 treated plants and also found that the apoplastic niche was occupied by $B$. licheniformis, (Table 8). This indicated the re-colonization of apoplastic bacteria after rhizobacterization.

Ralstonia pseudosolanacearum, being a universal pathogen infecting tomato, potato, tobacco, banana, ginger etc., various disease management strategies including cultural, chemical and biological control were attempted, however no complete success was obtained and due to the diverse species ecology, universal control measures are not feasible also (Saddler, 2005). $R$. solanacearum has been known for its multiplication in the xylem and intercellular sap, where the intercellular space is important in many biological functions like nutrient transport, plant pathogen interaction etc (Bakon and Hinton, 2006). So, in the current study the apoplastic fluid was extracted from the intercellular spaces of leaves and pseudostem of healthy ginger plants collected from various locations and also from germplasm collections. The vacuum infiltration and centrifugation technique was employed for the isolation of bacteria from the apoplastic fluid of ginger. The same technique was employed by Bell et al., 1995 to extract the xylem sap from the roots of grapevine and also by Gardner et al. 1982 from citrus plants. The infiltrationcentrifugation technique has been widely used for many plant species for intercellular fluid extraction due to efficiency and simplicity (Klement, 1965; Luwe et al., 1993; Lyons et al., 1999; Cheng et al., 2007; Nouchi et al., 2012). Dong et al. (1994) used centrifugation procedure for intercellular fluid extraction from sugar cane. The technique involved the selective isolation of bacteria colonized in the intercellular spaces and the xylem. Though the apoplastic fluid was plated in selective fungal and actinomycetes isolation medium, none of the culturable fungi or actinomycetes could be obtained.

In the present study, the population of apoplastic bacteria ranged from $3 \times 10^{1}$ to $3 \times 10^{3} \mathrm{~g}^{-1}$ in the pseudostems and zero to $2 \times 10^{3} \mathrm{~g}^{-1}$ in the leaves from ginger plants collected from different ginger growing tracts. Similarly, the population 
Table 8. Soil parameters and population of pathogen and antagonistic bacteria in rhizosphere soil, different plant tissues and apoplastic fluid in the pot experiment

\begin{tabular}{|c|c|c|c|c|c|c|c|c|c|c|c|c|c|}
\hline \multirow{2}{*}{$\begin{array}{l}\text { Treat- } \\
\text { ments }\end{array}$} & \multirow{2}{*}{$\mathrm{pH}$} & \multirow{2}{*}{$\begin{array}{c}\text { EC } \\
(\mu \mathrm{S})\end{array}$} & \multirow{2}{*}{$\begin{array}{c}\text { Dehydro- } \\
\text { genase } \\
\text { activity } \\
\text { ( } \mu \text { g TPF } \\
\text { g-1 soil/ } \\
\text { hour) }\end{array}$} & \multirow{2}{*}{$\begin{array}{c}\text { Rhizos- } \\
\text { phere } \\
\text { bacteria } \\
\text { other than } \\
\text { R. pseudo- } \\
\text { solanacear- } \\
\text { um (CFU } \\
\text { g-1) }\end{array}$} & \multirow{2}{*}{$\begin{array}{l}\text { R. pseu- } \\
\text { dosolan- } \\
\text { acearum } \\
\text { (CFU } \\
\text { g-1) }\end{array}$} & \multicolumn{2}{|c|}{$\begin{array}{l}\text { Root (CFU } \\
\text { g-1) }\end{array}$} & \multicolumn{2}{|c|}{$\begin{array}{l}\text { Rhizome } \\
\text { (CFU ml-1) }\end{array}$} & \multicolumn{2}{|c|}{$\begin{array}{c}\text { Pseudostem } \\
\text { Apoplastic } \\
\text { fluid (CFU } \\
\text { ml-1) }\end{array}$} & \multicolumn{2}{|c|}{$\begin{array}{l}\text { Leaf Apoplastic } \\
\text { fluid (CFU ml-1) }\end{array}$} \\
\hline & & & & & & TSA & $\begin{array}{c}\mathrm{TSA} \\
+ \\
\mathrm{NaCl}\end{array}$ & TSA & $\begin{array}{c}\mathrm{TSA} \\
+ \\
\mathrm{NaCl}\end{array}$ & TSA & $\begin{array}{c}\mathrm{TSA} \\
+ \\
\mathrm{NaCl}\end{array}$ & TSA & $\begin{array}{l}\mathrm{TSA}+ \\
\mathrm{NaCl}\end{array}$ \\
\hline $\begin{array}{l}\text { Pathogen } \\
\text { control** }\end{array}$ & 6.75 & 258 & 0.1211 & $9 \times 105$ & $2 \times 109$ & ND & $\mathrm{ND}$ & ND & ND & ND & ND & ND & ND \\
\hline $\begin{array}{l}\text { Absolute } \\
\text { control }\end{array}$ & 6.39 & 122.8 & 0.08075 & $1.6 \times 106$ & 0 & $\begin{array}{c}2.56 \\
\times \\
106\end{array}$ & $\begin{array}{l}7 \times \\
104\end{array}$ & $\begin{array}{c}5.67 \\
\times \\
104\end{array}$ & $\begin{array}{l}4 \times \\
104\end{array}$ & $\begin{array}{l}6 \times \\
102\end{array}$ & $\begin{array}{l}3 \times \\
102\end{array}$ & $\begin{array}{l}6 \times \\
102\end{array}$ & $4 \times 102$ \\
\hline $\begin{array}{l}\text { IISR } \\
\text { GAB } \\
107\end{array}$ & 6.7 & 176.5 & 0.3733 & $3.2 \times 106$ & $1.2 \times 103$ & $\begin{array}{l}2 \times \\
106\end{array}$ & $\begin{array}{c}3.7 \times \\
105\end{array}$ & $\begin{array}{c}4.15 \\
\times \\
106\end{array}$ & $\begin{array}{c}2.5 \times \\
105\end{array}$ & $\begin{array}{c}2.5 \times \\
103\end{array}$ & $\begin{array}{c}1.5 \times \\
103\end{array}$ & $\begin{array}{c}2.7 \\
\times \\
103\end{array}$ & $\begin{array}{c}1.6 \times \\
103\end{array}$ \\
\hline
\end{tabular}

*ND-not done as there were no plants left in pathogen control at the end of trial

** R. solanacearum inoculated control

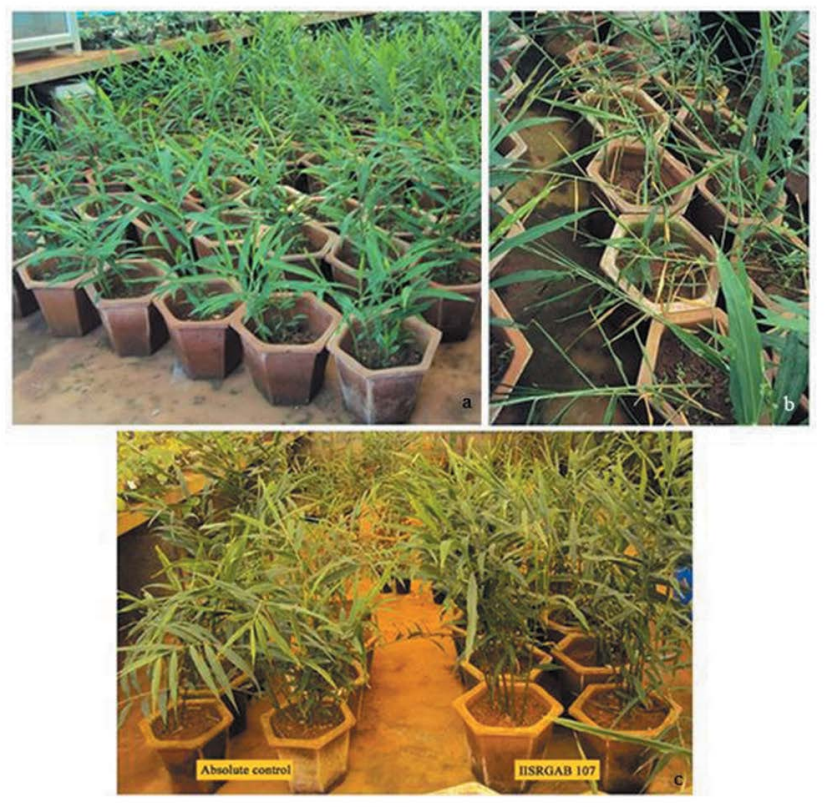

Fig. 4. Pot trial evaluation of apoplastic bacteria against bacterial wilt of ginger. (a) Forty five days old ginger plants in pots before Ralstonia pseudosolanacearum inoculation. (b) Bacterial wilt incidence after 15 days of pathogen inoculation. (c) Uninfected ginger plants treated with IISRGAB 107 in comparison with absolute control.

of apoplastic bacteria ranged from zero to $3 \times 10^{3} \mathrm{~g}^{-1}$ in the pseudostems and zero to $9.9 \times 10^{2} \mathrm{~g}^{-1}$ in the leaves from plants collected from different ginger germplasm accessions. Various researchers reported varying population level of endophytic bacteria according to the host plants. For example, alfalfa xylem tissue have $6.0 \times 10^{3}$ to $4.3 \times 10^{4} \mathrm{~g}^{-1}$ (Gagne et al., 1987), cotton xylem tissue have $1 \times 10^{2}$ to $11 \times 10^{3} \mathrm{~g}^{-1}$

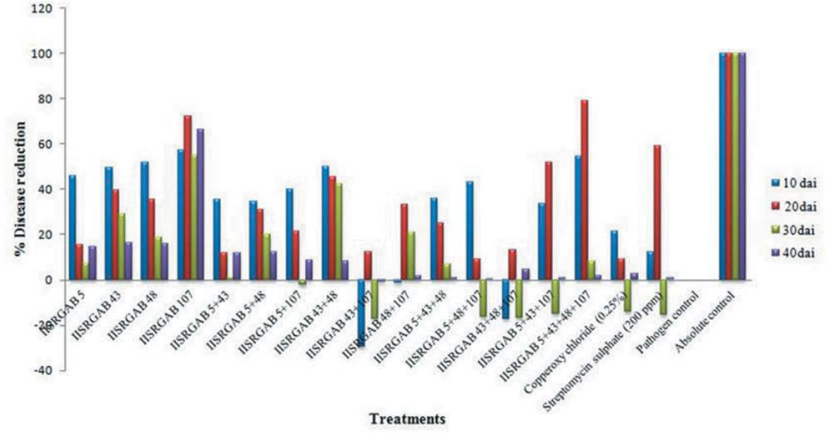

Fig 5. Graph showing bacterial wilt reduction by apoplastic bacteria.

(Misaghi and Donndelinger, 1990), sugar beet tissue have 3.3 $\times 10^{3}$ to $7.0 \times 10^{5} \mathrm{~g}^{-1}$ (Jacobs et al., 1985) and potato tubers have 0 to $1.6 \times 10^{4} \mathrm{~g}^{-1}$ (De Boer and Copeman, 1974). Considering the population level of endophytic bacteria in the apoplastic fluid, the number is less than the endophytic population obtained by trituration of homogenized plant tissues as already reported by Gardner et al. (1982) and Hallmann et al. (1997a). Even if some variations observed in the population level, this may be due to the selected solid agar medium and incubation conditions employed in the current study. Also, Bell et al. (1995) observed a lower population of endophytic bacteria isolated in solid medium up on vacuum extraction from grape vine stem when compared with direct staining with acridine orange or tissue maceration and plating on solid media. The difference in the population level of endophytes among different ginger samples may be due to the difference in geographic location and the environmental factors from where the plants were collected. The plants collected from germplasm bank showed difference in the endophytic 
colonization, which may be due to the original location from where these accessions were collected. This shows the diversity of indigenous endophytic population within a plant species. Chen et al. (2014) studied the population density and distribution of endophytic bacteria from different plant parts at three growth stages of ginger viz. seedling stage, vigorous growth stage and rhizome enlargement stage. They observed a higher colonization of endophytes at the seedling stage both in number and diversity and it was reduced when plant growth occurred. The prominent genera were Bacillus and Pseudomonas, both of which were found in all growth stages.

Of the 150 bacteria isolated from ginger pseudostems and leaves, $43.3 \%$ were gram positive rods and $38 \%$ were gram negative rod which is in accordance with the endophytic bacteria isolated from corn roots which consisted of $88 \%$ Gram positive bacteria (Lalande et al., 1989). Similar observations were made by Zinniel et al., (2002) from corn stalks and Aravind et al. (2009) from black pepper. However, the population diversity was contradictory to the reported population of endophytic bacteria from different plants like grapevine, citrus, corn, cotton, tomato, chilli, eggplant etc (Bell et al., 1995; Gardner et al., 1982; Hallmann et al., 1997; Amaresan et al., 2012; Achari and Ramesh, 2014; Upreti and Thomas, 2015).

Each bacterium has its own collection of enzymes that enable them to use diverse carbohydrates. This is often exploited in the identification of bacterial species. ( $w w w 2$. muw.edu/ /brandon/Micro/carbs.doc). Based on the sugar utilization pattern the apoplastic bacteria isolated were grouped into 22 groups which include the families viz. Bacillaceae, Lactobacillaceae, Enterobacteriaceae, Pseudomonadaceae, Aeromonadaceae, Moraxellaceae, Rhizobiaceae, Staphylococcaceae and Micrococcaceae.

The result of both in vitro and in planta screening clearly revealed that all the apoplastic inhabitants are not always antagonistic to the invading pathogens. Most of them may coexist with the pathogen while some of them resist the pathogen by antibiosis or by systemic resistance or competition for space and nutrients as shown by IISRGAB 24, IISRGAB 48 and IISRGAB 107. The lack of inhibition may be due to the inability of the apoplastic resident to grow in pace with the fast multiplication of the pathogen.

When the six bacteria were screened for production of diffusible inhibitory compounds like siderophore and hydrogen cyanide, it was found that most of the isolates are producing siderophores, but none of them are producing HCN. Similar observations were reported in case of endophytes associated with sugar cane by Mendes et al. (2007). Two of the Bacillus isolates IISRGAB 5 and
IISRGAB 107 could produce acetoin by glucose metabolism. Acetoin is an important volatile organic compound produced by plant associated bacteria, which has been reported as one of the elicitor of induced systemic resistance in plants up on pathogen inoculation (Kim et al., 2011). The studies conducted by Rudrappa et al. (2010) on Arabidopsis thaliana showed that Bacillus subtilis strain FB17 derived acetoin, triggered induced systemic resistance in plants when infected with Pseudomonas syringae pv. tomato. Though in small quantities, all the six isolates, short listed in our study, could produce ammonia and IAA which has a crucial role in plant growth and its additional supply can support the host in stress conditions like drought and pathogen attack (Belimov et al., 2015).

16S rDNA sequence identification revealed two of the six isolates as $A$. tumefaciens and $S$. haemolyticus, which were also isolated from the xylem sap of egg plant and chilli (Achari and Ramesh, 2014). The occurrence of B. marisflavi as an endophyte of plant has been recorded for the first time in ginger. Earlier this bacterium has been isolated from yellow sea in South Korea (Yoon et al., 2003) and from agricultural waste in Tamil Nadu India (Anthony et al., 2014).

The short listed bacteria were used for the control of $R$. pseudosolanacearum under green house conditions individually and in consortia. In an initial trial (data not presented) there was $100 \%$ disease incidence and no yield could be recorded. This may be due to the insufficient colonization of the bacteria in the plant rhizosphere or endophytically. It was already reported in the case of some endophytes that even if the inoculum level is high but that whole population will not colonize endophytically. That means there is always an optimum holding capacity of the plants for endophytes, which may fluctuate according to the age of the plant and environmental factors (Hallmann et al., 1997). In the pot culture evaluation IISRGAB 107 (Bacillus licheniformis) could effectively reduce the wilt incidence by $65 \%$ over control. But when IISRGAB 107 was applied in combination with other apoplastic bacteria the concurring disease reduction is not happening. This may be due to the competition between these apoplastic bacteria for the same niche, which may play a role and may contribute to the inferior colonization of IISRGAB 107.

Diverse Bacillus species has been reported as effective biocontrol agents against plant pathogens (Lemessa and Zeller, 2007; Ji et al., 2008; Maketon et al., 2008). Bacillus subtilis has been in use in mulberry and tobacco against $R$. pseudosolanacearum (Ji, 2008; Lemessa and Zeller, 2007; Maketon et al., 2008) in tomato against Xanthomonas euvesicatoria and Xanthomonas perforans (Roberts et al., 2008) and also against various fungal pathogens and plant 
pathogenic nematodes (Cawoy et al., 2011). There are also reports that $B$. licheniformis has been effectively employed for the control of strawberry gray mold and tomato gray mold caused by Botrytis cinerea (Kim et al., 2007; Lee et al, 2006). Later Kong et al. (2010) identified two major compounds iturin $A$ and surfactin, from $B$. licheniformis strain N1, showing antifungal activity against many fungal pathogens. Also $B$. licheniformis has been used as a biofungicide against Colletotrichum graminicola and Sclerotinia homeocarpa in turf farms and arboretum (Cawoy et al., 2011). Amaresan et al. (2014) reported $B$. licheniformis from chilli was effective in reducing the major diseases of chilli. B. licheniformis strain GL174 an endophyte from Vitis vinifera has been studied extensively for its endophytic nature and biocontrol properties against the major fungal pathogens of host (Nilgris et al., 2018) Hence to conclude, B. licheniformis strain IISRGAB 107 identified in this study is promising, possessing major growth promoting traits as well as biocontrol traits, can be effectively used for developing a bactericide for controlling bacterial wilt of ginger.

\section{Identity confirmation of IISRGAB 5 (Bacillus subtilis) and IISRGAB 107 (Bacillus licheniformis) using salt tol- erance test}

When 16S rDNA sequences were analysed by blasting in NCBI Blastn (http://www.ncbi.nlm.nih.gov/BLAST), programme, IISRGAB 5 showed 99\% similarity towards both B. subtilis and B. amyloliquefaciens and IISRGAB 107 showed 99\% similarity towards B. licheniformis and B. sonorensis. In order to confirm the exact identity of the bacteria tolerance to $\mathrm{NaCl}$ was done. According to Welker and Campbell (1967), B. subtilis vary from B. amyloliquifaciens in salt tolerance i.e. B. subtilis cannot grow in a medium containing $10 \% \mathrm{NaCl}$ but $B$. amyloliquefaciens can grow. So nutrient broth was prepared with differential concentrations of $\mathrm{NaCl}(0.5 \%, 2 \%, 4 \%, 8 \%$, and $10 \%)$ and pure colony of IISRGAB 5 was inoculated in each flask and incubated in an orbital shaker at $280 \mathrm{C}$ at $180 \mathrm{rpm}$ for 3-5 days. Based on the salt tolerance test, it was found that IISRGAB 5 could tolerate only up to $8 \% \mathrm{NaCl}$ amended nutrient broth. There is no growth in $10 \% \mathrm{NaCl}$ even after 5 days of incubation (Figure 3-4b). So, this confirmed the identity of IISRGAB 5 as B. subtilis Similarly Palmisano et al. (2001) reported that salt tolerance is a method to distinguish $B$. sonorensis from B. licheniformis. B. sonorensis can tolerate only up to $3 \%$ $\mathrm{NaCl}$ in the medium, while $B$. licheniformis can tolerate up to $10 \% \mathrm{NaCl}$. Accordingly tryptic soy broth was prepared with different concentrations of $\mathrm{NaCl}$ ranging from $1 \%$ to $10 \%$. IISRGAB 107 was inoculated into each concentration and incubated in an orbital shaker at $28^{\circ} \mathrm{C}$ at $180 \mathrm{rpm}$ for 7 days. Turbidity was observed in all concentrations within 24 hours of incubation. So, it is clear that IISRGAB 107 can tolerate up to $10 \% \mathrm{NaCl}$. Hence, the identity of the bacterium was confirmed as Bacillus licheniformis.

\section{CONCLUSION}

Among the 150 bacteria isolates from ginger apoplastic fluid, only one isolate namely GAB107 identified as Bacillus licheniformis was found to be a potential candidate against Ralstonia psuedosolanacearum. Since bacterial wilt of ginger is a threatening problem and increased and non-judicoius and indiscrimnate application of plant protection chemicals spoil the nature, it is suggested to scale up the dissemination of this biocontrol agents for saving the nature as well as to save the farmers from bacterial wilt crisis.

\section{ACKNOWLEDGEMENT}

The authors are grateful to Outreach programme on Phytophthora, Fusarium and Ralstonia diseases of Horticultural and Field Crops (PhytoFuRa) funded by Indian council of Agricultural research (ICAR), New Delhi. Various facilities provided by the Director ICAR-IISR, Kozhikode are thankfully acknowledged.

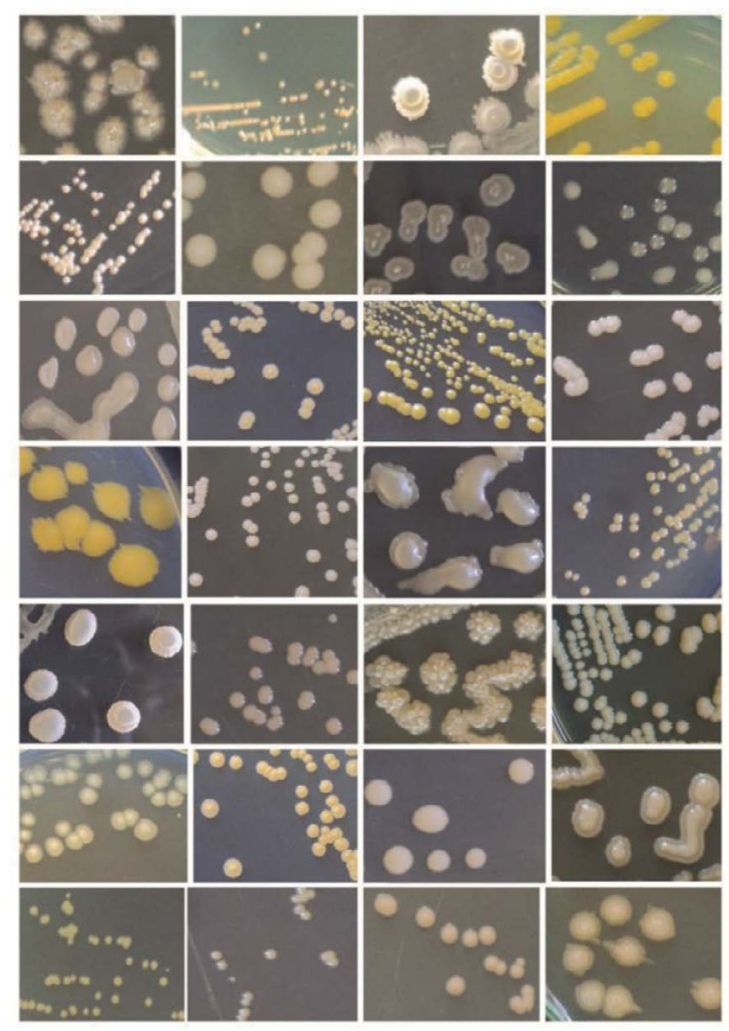

Supplementary Fig. 1. Colony morphology of ginger apoplastic bacteria on tryptic soy agar. 

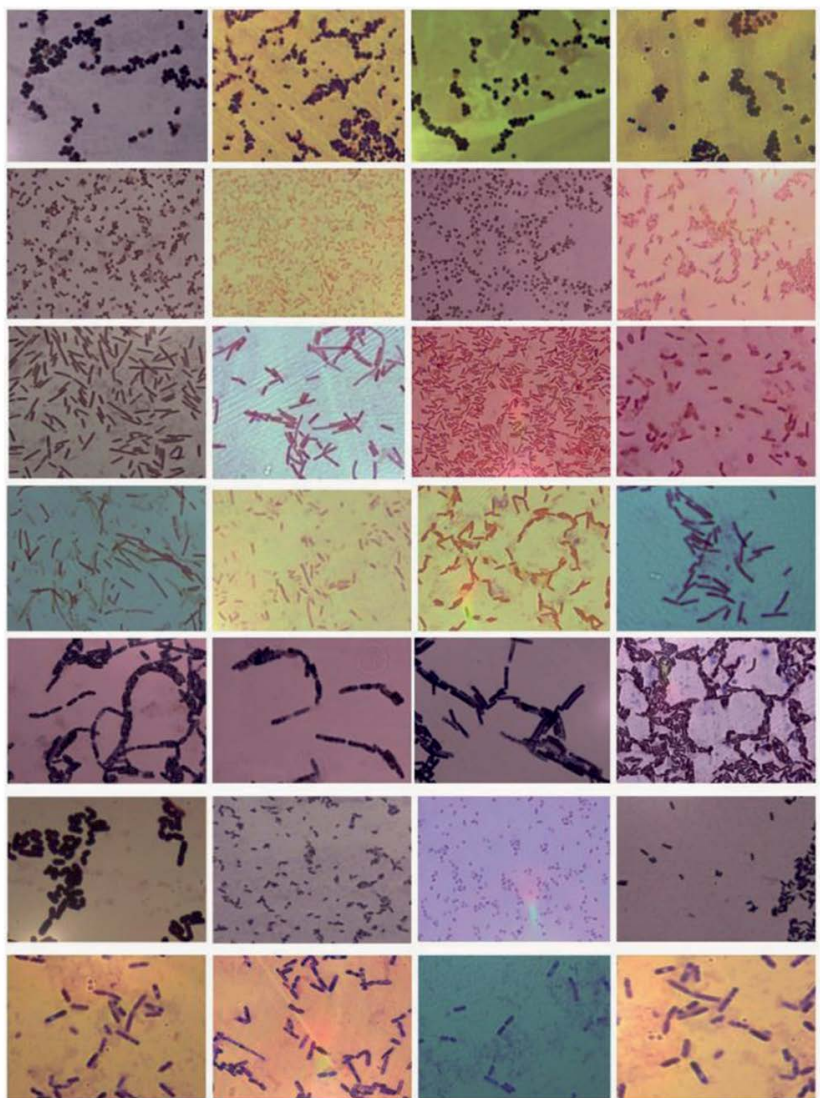

Supplementary Fig. 2. Microscopic appearance of Gram stained cells of apoplastic bacteria
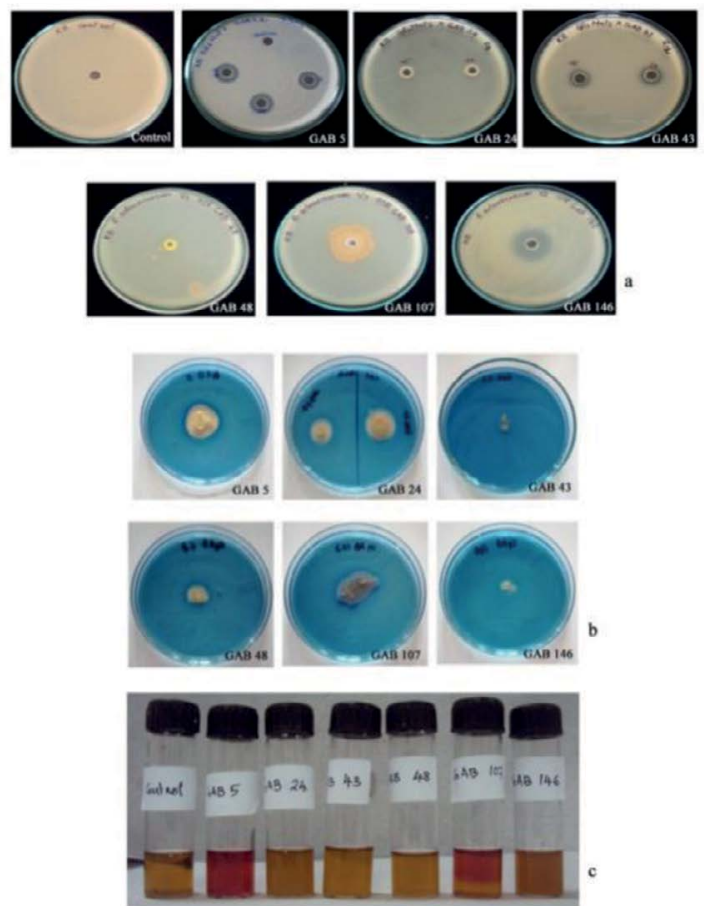

Supplementary Fig. 3. Characterization of apoplastic bacteria for biocontrol traits a. antibiosis by agar well diffusion method b. siderophore production c. Acetoin production.
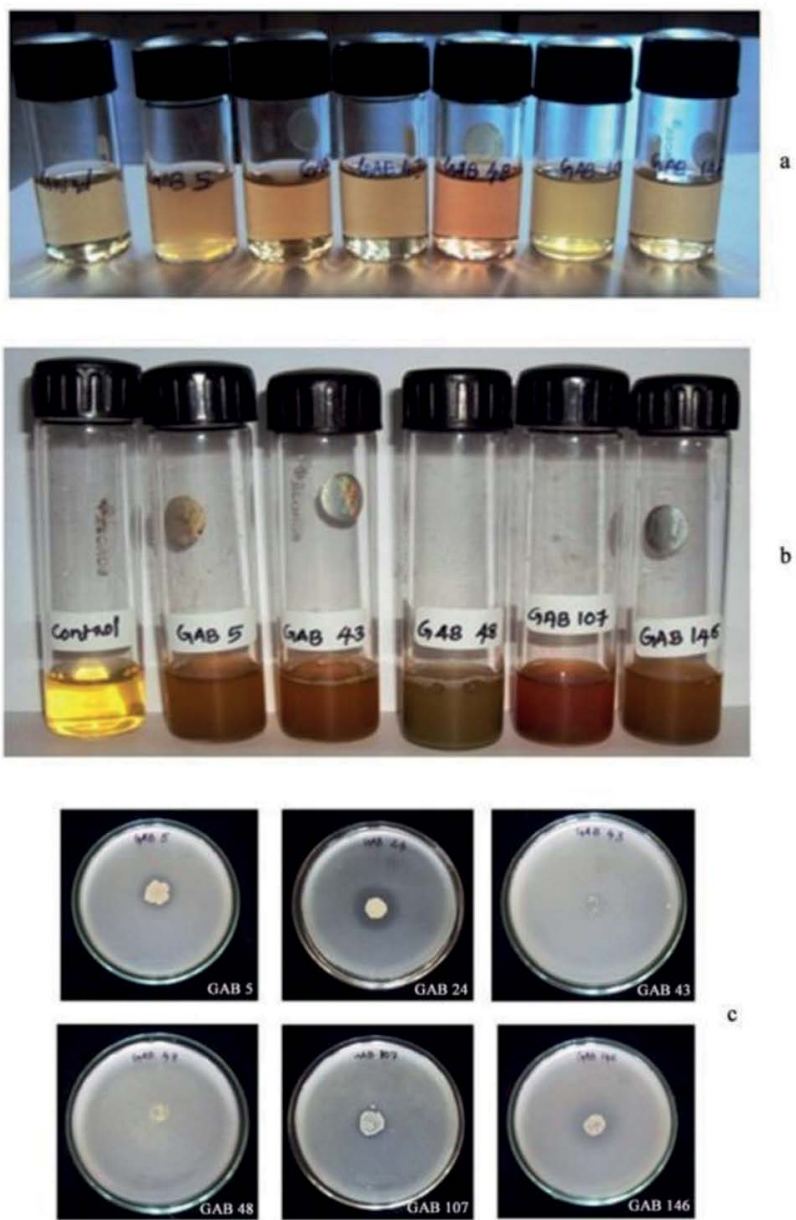

Supplementary Fig. 4. Characterization of apoplastic bacteria for with promoting traits. a. IAA production b. Ammonia production c. Phosphate solubilization.

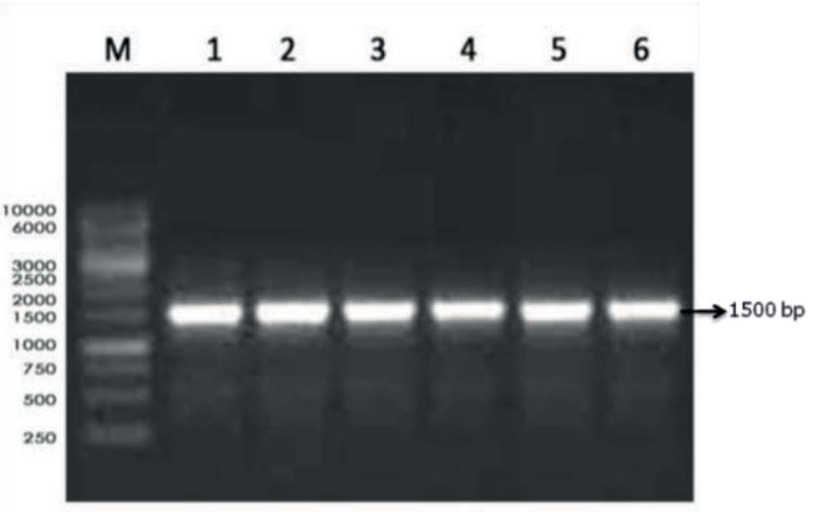

Supplementary Fig. 5. Gel image showing the 1500 bp amplicon of partial 16s rDNA gene of short listed apoplastic bacteria. 
Supplementary Table 1. In vitro, in planta screening and siderophore production of apoplastic bacteria against Ralstonia solanacearum race 4

\begin{tabular}{|c|c|c|c|c|c|c|c|c|c|}
\hline Isolate No. & $\begin{array}{l}\text { In vitro } \\
\text { screening } \\
\text { (inhibition } \\
\text { zone) }\end{array}$ & $\begin{array}{c}\text { Sidero- } \\
\text { phore }\end{array}$ & $\begin{array}{l}\text { In planta } \\
\text { screening }\end{array}$ & $\begin{array}{c}\text { Isolate } \\
\text { No. }\end{array}$ & $\begin{array}{c}\text { In vitro } \\
\text { screening }\end{array}$ & Siderophore & $\begin{array}{l}\text { In } \\
\text { planta } \\
\text { screen- } \\
\text { ing }\end{array}$ & & \\
\hline & & & $\begin{array}{c}\text { Disease } \\
\text { incidence } \\
(\%)\end{array}$ & $\begin{array}{l}\text { Days } \\
\text { taken } \\
\text { for } \\
\text { wilting }\end{array}$ & & & & $\begin{array}{c}\text { Disease } \\
\text { incidence } \\
(\%)\end{array}$ & $\begin{array}{l}\text { Days taken } \\
\text { for wilting }\end{array}$ \\
\hline IISRGAB 1 & No inhibition & $+(3)$ & 100 & 10 & IISRGAB 47 & No inhibition & $+(4)$ & 80 & 30 \\
\hline IISRGAB 2 & No inhibition & $+(2)$ & 66.66 & 10 & IISRGAB 48 & No inhibition & $+(3)$ & 0 & No symptoms \\
\hline IISRGAB 3 & No inhibition & $+(1)$ & 75 & 13 & IISRGAB 49 & No inhibition & $+(3)$ & 100 & 27 \\
\hline IISRGAB 4 & No inhibition & $+(1)$ & 75 & 19 & IISRGAB 50 & No inhibition & + & 100 & 10 \\
\hline IISRGAB 5 & 10.0 & $+(7)$ & 40 & 30 & IISRGAB 51 & No inhibition & $+(2)$ & 85.7 & 13 \\
\hline IISRGAB 6 & No inhibition & $+(2)$ & 100 & 19 & IISRGAB 52 & No inhibition & - & 100 & 10 \\
\hline IISRGAB 7 & No inhibition & $-(0)$ & 83.33 & 19 & IISRGAB 53 & No inhibition & $+(2)$ & 100 & 10 \\
\hline IISRGAB 8 & No inhibition & $+(3)$ & 80 & 23 & IISRGAB 54 & No inhibition & $+(2)$ & 100 & 10 \\
\hline IISRGAB 9 & No inhibition & $+(2)$ & 83.33 & 23 & IISRGAB 55 & No inhibition & $+(2)$ & 100 & 10 \\
\hline IISRGAB 10 & No inhibition & $+(2)$ & 100 & 19 & IISRGAB 56 & No inhibition & $+(3)$ & 100 & 23 \\
\hline IISRGAB 11 & No inhibition & - & 71.42 & 19 & IISRGAB 57 & No inhibition & $+(1)$ & 100 & 23 \\
\hline IISRGAB 12 & No inhibition & $+(3)$ & 75 & 30 & IISRGAB 58 & No inhibition & $+(4)$ & 85.7 & 19 \\
\hline IISRGAB 13 & No inhibition & $+(4)$ & 75 & 13 & IISRGAB 59 & No inhibition & $+(3)$ & 100 & 30 \\
\hline IISRGAB 14 & No inhibition & $+(1)$ & 66.66 & 10 & IISRGAB 60 & No inhibition & $+(1)$ & 83.3 & 10 \\
\hline \multicolumn{10}{|l|}{ IISRG } \\
\hline $\mathrm{AB} 15$ & No inhibition & $+(2)$ & 71.42 & 10 & IISRGAB 61 & No inhibition & $+(1)$ & 100 & 13 \\
\hline IISRGAB 16 & No inhibition & - & 80 & 10 & IISRGAB 62 & No inhibition & $+(1)$ & 100 & 10 \\
\hline IISRGAB 17 & No inhibition & - & 80 & 19 & IISRGAB 63 & No inhibition & $+(2)$ & 100 & 13 \\
\hline IISRGAB 18 & No inhibition & $+(2)$ & 83.33 & 19 & IISRGAB 64 & No inhibition & $+(2)$ & 100 & 13 \\
\hline IISRGAB 19 & No inhibition & $+(2)$ & 100 & 10 & IISRGAB 65 & No inhibition & - & 100 & 27 \\
\hline IISRGAB 20 & No inhibition & $+(2)$ & 100 & 10 & IISRGAB 66 & No inhibition & $+1)$ & 100 & 19 \\
\hline IISRGAB 21 & No inhibition & - & 75 & 10 & IISRGAB 67 & No inhibition & $+(1)$ & 100 & 13 \\
\hline IISRGAB 22 & No inhibition & - & 100 & 19 & IISRGAB 68 & No inhibition & $+(1)$ & 100 & 19 \\
\hline IISRGAB 23 & No inhibition & $+(2)$ & 100 & 13 & IISRGAB 69 & No inhibition & - & 100 & 19 \\
\hline IISRGAB 24 & No inhibition & $+(5)$ & 0 & 0 & IISRGAB 70 & No inhibition & $+(1)$ & 87.5 & 19 \\
\hline IISRGAB 25 & No inhibition & $+(1)$ & 83.33 & 13 & IISRGAB 71 & No inhibition & $+(4)$ & 85.7 & 13 \\
\hline IISRGAB 26 & No inhibition & - & 71.42 & 13 & IISRGAB 72 & No inhibition & $+(4)$ & 100 & 13 \\
\hline IISRGAB 27 & No inhibition & - & 80 & 19 & IISRGAB 73 & No inhibition & $+(4)$ & 100 & 13 \\
\hline IISRGAB 28 & No inhibition & $+(2)$ & 100 & 23 & IISRGAB 74 & No inhibition & $+(1)$ & 100 & 13 \\
\hline IISRGAB 29 & No inhibition & - & 80 & 27 & IISRGAB 75 & No inhibition & $+(3)$ & 83.3 & 23 \\
\hline IISRGAB 30 & No inhibition & $+(3)$ & 83.33 & 27 & IISRGAB 76 & No inhibition & $+(3)$ & 100 & 10 \\
\hline IISRGAB 31 & No inhibition & $+(1)$ & 100 & 27 & IISRGAB 77 & No inhibition & $+(2)$ & 100 & 10 \\
\hline IISRGAB 32 & No inhibition & $+(2)$ & 100 & 13 & IISRGAB 78 & No inhibition & $+(2)$ & 100 & 10 \\
\hline IISRGAB 33 & 2.0 & $+(3)$ & 100 & 27 & IISRGAB 79 & No inhibition & $+(1)$ & 100 & 13 \\
\hline IISRGAB 34 & No inhibition & - & 80 & 27 & IISRGAB 80 & No inhibition & $+(1)$ & 100 & 13 \\
\hline IISRGAB 35 & No inhibition & $+(2)$ & 80 & 19 & IISRGAB 81 & No inhibition & $+(1)$ & 100 & 13 \\
\hline
\end{tabular}




\begin{tabular}{|c|c|c|c|c|c|c|c|c|c|}
\hline IISRGAB 36 & No inhibition & $+(1)$ & 100 & 10 & IISRGAB 82 & No inhibition & $+(1)$ & 100 & 13 \\
\hline IISRGAB 37 & No inhibition & $+(2)$ & 100 & 10 & IISRGAB 83 & No inhibition & $+(1)$ & 87.5 & 19 \\
\hline IISRGAB 38 & No inhibition & - & 100 & 13 & IISRGAB 84 & No inhibition & $+(5)$ & 100 & 10 \\
\hline IISRGAB 39 & No inhibition & $+(2)$ & 80 & 13 & IISRGAB 85 & No inhibition & $+(2)$ & 100 & 19 \\
\hline IISRGAB 40 & No inhibition & $+(3)$ & 100 & 13 & IISRGAB 86 & No inhibition & $+(2)$ & 100 & 19 \\
\hline IISRGAB 41 & No inhibition & - & 100 & 13 & IISRGAB 87 & No inhibition & $+(3)$ & 100 & 10 \\
\hline IISRGAB 42 & No inhibition & - & 100 & 19 & IISRGAB 88 & No inhibition & $+(2)$ & 85.7 & 13 \\
\hline IISRGAB 43 & No inhibition & - & 20 & 23 & IISRGAB 89 & No inhibition & $+(1)$ & 85.7 & 10 \\
\hline IISRGAB 44 & No inhibition & $+(1)$ & 80 & 13 & IISRGAB 90 & No inhibition & $+((1)$ & 100 & 30 \\
\hline IISRGAB 45 & No inhibition & $+(1)$ & 80 & 13 & IISRGAB 91 & No inhibition & $+(2)$ & 100 & 13 \\
\hline IISRGAB 46 & No inhibition & - & 75 & 13 & IISRGAB 92 & No inhibition & $+(2)$ & 100 & 10 \\
\hline IISRGAB 93 & No inhibition & - & 100 & 19 & IISRGAB 122 & No inhibition & $+(6)$ & 100 & 27 \\
\hline IISRGAB 94 & No inhibition & $+(2)$ & 85.71 & 30 & IISRGAB 123 & No inhibition & - & 100 & 19 \\
\hline IISRGAB 95 & No inhibition & $+(2)$ & 100 & 13 & IISRGAB 124 & No inhibition & $+(2)$ & 100 & 19 \\
\hline IISRGAB 96 & No inhibition & $+(3)$ & 87.5 & 10 & IISRGAB 125 & No inhibition & - & 100 & 23 \\
\hline IISRGAB 97 & No inhibition & $+(2)$ & 100 & 10 & IISRGAB 126 & No inhibition & $+(2)$ & 100 & 10 \\
\hline IISRGAB 98 & No inhibition & - & 100 & 13 & IISRGAB 127 & No inhibition & - & 100 & 23 \\
\hline IISRGAB 99 & No inhibition & $+(5)$ & 100 & 13 & IISRGAB 128 & No inhibition & - & 100 & 13 \\
\hline IISRGAB 100 & No inhibition & $+(3)$ & 100 & 13 & IISRGAB 129 & No inhibition & $+(2)$ & 100 & 13 \\
\hline IISRGAB 101 & No inhibition & $+(2)$ & 100 & 30 & IISRGAB 130 & No inhibition & - & 83.3 & 23 \\
\hline IISRGAB 102 & No inhibition & - & 100 & 10 & IISRGAB 131 & No inhibition & - & 100 & 10 \\
\hline IISRGAB 103 & No inhibition & - & 100 & 30 & IISRGAB 132 & No inhibition & $+(2)$ & 100 & 19 \\
\hline IISRGAB 104 & No inhibition & - & 100 & 13 & IISRGAB 133 & No inhibition & - & 100 & 13 \\
\hline IISRGAB 105 & No inhibition & - & 100 & 19 & IISRGAB 134 & No inhibition & - & 100 & 13 \\
\hline IISRGAB 106 & No inhibition & - & 100 & 13 & IISRGAB 135 & No inhibition & - & 100 & 19 \\
\hline IISRGAB 107 & No inhibition & $+(3)$ & 0 & 0 & IISRGAB 136 & No inhibition & $+(2)$ & 100 & 13 \\
\hline IISRGAB 108 & No inhibition & $+(6)$ & 100 & 13 & IISRGAB 137 & No inhibition & $+(4)$ & 100 & 19 \\
\hline IISRGAB 109 & No inhibition & $+(2)$ & 100 & 23 & IISRGAB 138 & No inhibition & $+(3)$ & 100 & 13 \\
\hline IISRGAB 110 & No inhibition & - & 100 & 13 & IISRGAB 139 & No inhibition & $+(5)$ & 100 & 10 \\
\hline IISRGAB 111 & No inhibition & $+(4)$ & 100 & 23 & IISRGAB 140 & No inhibition & $+(4)$ & 83.3 & 23 \\
\hline IISRGAB 112 & No inhibition & - & 100 & 10 & IISRGAB 141 & No inhibition & $+(2)$ & 75 & 13 \\
\hline IISRGAB 113 & No inhibition & $+(6)$ & 100 & 19 & IISRGAB 142 & No inhibition & $+(1)$ & 80 & 10 \\
\hline IISRGAB 114 & No inhibition & - & 100 & 23 & IISRGAB 143 & No inhibition & $+(3)$ & 100 & 10 \\
\hline IISRGAB 115 & No inhibition & - & 100 & 10 & IISRGAB 144 & No inhibition & $+(4)$ & 100 & 13 \\
\hline IISRGAB 116 & No inhibition & $+(2)$ & 100 & 19 & IISRGAB 145 & No inhibition & $+(4)$ & 80 & 13 \\
\hline IISRGAB 117 & No inhibition & $+(2)$ & 100 & 10 & IISRGAB 146 & 5.0 & - & 50 & 30 \\
\hline IISRGAB 118 & No inhibition & - & 100 & 23 & IISRGAB 147 & No inhibition & $+(3)$ & 100 & 30 \\
\hline IISRGAB 119 & No inhibition & - & 100 & 10 & IISRGAB 148 & No inhibition & $+(3)$ & 100 & 23 \\
\hline IISRGAB 120 & No inhibition & $+3)$ & 100 & 10 & IISRGAB 149 & No inhibition & $+4)$ & 100 & 13 \\
\hline IISRGAB 121 & No inhibition & - & 88.88 & 10 & IISRGAB 150 & No inhibition & $+(3)$ & 100 & 19 \\
\hline $\begin{array}{c}\text { Absolute } \\
\text { Control }\end{array}$ & - & & 0 & 0 & $\begin{array}{c}\text { Pathogen } \\
\text { control }\end{array}$ & - & & 100 & 10 \\
\hline
\end{tabular}

- not present

+ present (nos. in brackets represents. zone diameter in $\mathrm{cm}$ ) 


\section{REFERENCES}

Achari GA, Ramesh R. 2014. Diversity, biocontrol, and plant growth promoting abilities of xylem residing bacteria from solanaceous crops. Int $J$ Microbiol. 14: doi: 10.1155/2014/296521 https://doi.org/10.1155/2014/296521 PMid:24963298 PMCid:PMC4055287

Amaresan N, Jayakumar V, Thajuddin N. 2014. Isolation and characterization of endophytic bacteria associated with chilli (Capsicum annuum) grown in coastal agricultural ecosystem. Indian J Biotechnol.13: 247-255

Amaresan N, Jayakumar V, Kumar K, Thajuddin N. 2012. Endophytic bacteria from tomato and chilli, their diversity and antagonistic potential against Ralstonia solanacearum. Arch Phytopathol Plant Prot. 45 (3): 344-355 https://doi.org/10.1080/03235408.2011.5872 73

Aneja KR. 2003. Experiments in microbiology, plant pathology and biotechnology. New Age International Publishers

Apun K, Jong BC, Salleh MA. 2000. Screening and isolation of a cellulolytic and amylolytic Bacillus from sago pith waste. J Gen Appl Microbiol. 46(5): 263-267 https://doi. org/10.2323/jgam.46.263 PMid:12483578

Anthony KJP, Murugan M, Gurunathan S. 2014. Biosynthesis of silver nanoparticles from the culture supernatant of Bacillus marisflavi and their potential antibacterial activity. J Indust Eng Chem. 20(4):1505-1510 https:// doi.org/10.1016/j.jiec.2013.07.039

Aravind R, Antony D, Eapen, SJ, Kumar A, Ramana KV, 2009. Isolation and evaluation of endophytic bacteria against plant parasitic nematodes infesting black pepper (Piper nigrum L.). Indian J Nematol. 39(2):211-217.

Bacon CW and Hinton DM. 2006. Bacterial endophytes: The endophytic niche, its occupants, and its utility. pp. 155194. In: Gnanamanickam SS (Eds.). Plant-Associated Bacteria. Springer; Netherlands.

Bacon CW, Hinton DM. 2002. Endophytic and biological control potential of Bacillus mojavensis and related species. Biol Control. 23(3): 274-284 https://doi. org/10.1006/bcon.2001.1016

Bell CR., Dickie GA, Harvey WLG, Chan JWYF. 1995. Endophytic bacteria in grapevine. Can J Microbiol. 41(1): 46-53. https://doi.org/10.1139/m95-006
Barretti PB, de Souza RM, Pozza EA, de Souza JT (2012) Combination of endophytic bacteria and resistant cultivars improves control of Ralstonia wilt of tomato. Australas Plant Pathol. 41(2): 189-195 https://doi. org/10.1007/s13313-011-0107-1

Belimov AA, Dodd IC, Safronova VI, Shaposhnikov AI, Azarova TS, Makarova NM, Davies WJ, Tikhonovich, IA. 2015. Rhizobacteria that produce auxins and contain 1 amino cyclopropane 1 carboxylic acid deaminase decrease amino acid concentrations in the rhizosphere and improve growth and yield of well watered and water limited potato (Solanum tuberosum). Ann Appl Biol. 67(1):11-25 https://doi.org/10.1111/aab.12203

Cappuccino JC, Sherman N. 1992 Microbiology: A Laboratory Manual. $3^{\text {rd }}$ ed. Benjamin/cummings Pub. Co. pp. New York: 125-179.

Cappuccino JG, Sherman N. 2005. Microbiology: A Laboratory Manual. $7^{\text {th }}$ ed. Benjamin Cummings: Pearson Education, Inc. New York

Casida Jr LE, Klein DA, Santoro T. 1964. Soil dehydrogenase activity. Soil Sci. 98(6): 371-376 https://doi. org/10.1097/00010694-196412000-00004

Cawoy H, Bettiol W, Fickers P, Ongena M. 2011. Bacillusbased biological control of plant diseases. pp. 273-302, In: Stoytcheva M (Ed.). Pesticides in the modern worldpesticides use and management. InTech, Rijeka, Croatia. https://doi.org/10.5772/17184

Cheng FY, Burkey KO, Robinson JM, Booker FL. 2007. Leaf extracellular ascorbate in relation to $\mathrm{O} 3$ tolerance of two soybean cultivars. Environ Pollut. 150(3):355362. https://doi.org/10.1016/j.envpol.2007.01.022 PMid:17442469

Clarke PH, Cowan ST. 1952. Biochemical methods for bacteriology. Microbiology 6(1-2): 187-197 https://doi. org/10.1099/00221287-6-1-2-187 PMid:14927866

Collins CH, Lyne PM, Grange JM. 1995. Collins and Lyne's Microbiological Methods, 7th ed. ButterworthHeinemann, UK, pp. 114

De Boer SH, Copeman RJ, 1974. Endophytic bacterial flora in Solanum tuberosum and its significance in bacterial ring rot disease. Can J Plant Sci. 54: 115- $122 \mathrm{https}: / /$ doi.org/10.4141/cjps74-019

Dong Z, Canny MJ, McCully ME, Roboredo MR, Cabadilla CF, Ortega E. Rodes R. 1994. A nitrogen-fixing endophyte of sugarcane stems (a new role for the apoplast). Plant 
Physiol. 105(4): 1139-1147 https://doi.org/10.1104/ pp.105.4.1139 PMid:12232271 PMCid:PMC159442

Engelbrecht MC. 1994. Modification of a semi-selective medium for the isolation and quantification of Pseudomonas solanacearum. ACIAR Bacterial Wilt Newsletter. 10: 3-5

Feng H, Li Y, Liu Q. 2013. Endophytic bacterial communities in tomato plants with differential resistance to Ralstonia solanacearum. Afr J Microbiol Res. 7(15): 1311-1318 https://doi.org/10.5897/AJMR12.375

Gagne S, Richard C, Rousseau H, Antoun H. 1987. Xylemresiding bacteria in alfalfa roots. Can $J$ Microbiol. 33(11): 996-1000. https://doi.org/10.1139/m87-175

Gardner JM, Feldman AW, Zablotowicz RM. 1982. Identity and behavior of xylem-residing bacteria in rough lemon roots of Florida citrus trees. App Environ Microbiol. 43(6): 1335-1342.

Gaur AC. 1990. Physiological functions of phosphate solubilising microorganisms. pp. 16-72. In: Gaur AC (Ed.). Phosphate solubilising microorganisms as biofertilizers. Omega Scientific publishers. New Delhi,

Hallmann J, Quadt-Hallmann A, Mahaffee WF, Kloepper JW. 1997. Bacterial endophytes in agricultural crops. Can J Microbiol. 43(10): 895-914 https://doi.org/10.1139/ m97-131

Hallmann J, Kloepper JW, Rodriguez-Kabana R. 1997a. Application of the Scholander pressure bomb to studies on endophytic bacteria of plants. Can J Microbiol. 43(5): 411-416. https://doi.org/10.1139/m97-058

Jasim B, Joseph AA, John CJ, Mathew J, Radhakrishnan EK. 2014. Isolation and characterization of plant growth promoting endophytic bacteria from the rhizome of Zingiber officinale. 3 Biotech 4(2): 197-204 https:// doi.org/10.1007/s13205-013-0143-3 PMid:28324450 PMCid:PMC3964247

Ji X, Lu G, Gai Y, Zheng C, Mu Z. 2008. Biological control against bacterial wilt and colonization of mulberry by an endophytic Bacillus subtilis strain. FEMS Microbiol Ecol. 65(3): 565-573 https://doi.org/10.1111/j.15746941.2008.00543.x PMid:18631174

Kim JH, Lee SH, Kim CS, Lim EK, Choi KH, Kong HG, Kim DW, Lee SW, Moon BJ. 2007. Biological control of strawberry gray mold caused by Botrytis cinerea using Bacillus licheniformis N1 formulation. J Microbiol Biotechnol. 17(3): 438-444.
Kim YC, Leveau J, Gardener BBM, Pierson EA, Pierson LS, Ryu CM. 2011. The multifactorial basis for plant health promotion by plant-associated bacteria. Appl Environ Microbiol. 77(5): 1548-1555 https://doi.org/10.1128/ AEM.01867-10 PMid:21216911 PMCid:PMC3067257

Klement Z. 1965. Method of obtaining fluid from the intercellular spaces of foliage and the fluid's merit as substrate for phytobacterials pathogens. Phytopathology 55: 1033-1034.

Kloepper JW, Reddy MS, Rodríguez-Kabana R, Kenney DS, Kokalis-Burelle N, Martinez-Ochoa N, Vavrina CS. 2004. Application for rhizobacteria in transplant production and yield enhancement. Acta Hortic. 217230 https://doi.org/10.17660/ActaHortic.2004.631.28

Kong HG, Kim JC, Choi GJ, Lee KY, Kim HJ, Hwang EC, Moon BJ, Lee SW. 2010. Production of surfactin and iturin by Bacillus licheniformis N1 responsible for plant disease control activity. Plant Pathol J. 26(2):170-177 https://doi.org/10.5423/PPJ.2010.26.2.170

Kumar A, Hayward AC. 2005. Bacterial diseases of ginger and their control. pp 341-366. In: Ravindran PN, Babu KN (Eds.). Monograph on Ginger. CRC Press, Boca Raton, FL, USA,

Lalande R, Bissonnette N, Coutlée D, Antoun H. 1989. Identification of rhizobacteria from maize and determination of their plant-growth promoting potential. Plant Soil 115(1): 7-11. https://doi.org/10.1007/ BF02220688

Lee JP, Lee SW, Kim CS, Son JH, Song JH, Lee KW, Kim HJ, Jung SJ, Moon BJ. 2006. Evaluation of formulations of Bacillus licheniformis for the biological control tomato gray mold caused by Botrytis cinerea. Biol Control. 37(3): 329-337 https://doi.org/10.1016/j. biocontrol.2006.01.001

Lemessa F, Zeller W. 2007. Screening rhizobacteria for biological control of Ralstonia solanacearum in Ethiopia. Biol Control. 42(3): 336-344 https:/doi. org/10.1016/j.biocontrol.2007.05.014

Lemos ML, Toranzo AE, Barja JL. 1985. Antibiotic activity of epiphytic bacteria isolated from intertidal seaweeds. Microb Ecol. 11(2): 149-163 https://doi.org/10.1007/ BF02010487 PMid:24221303

Lorck H. 1948. Production of hydrocyanic acid by bacteria. Plant Physiol. 1(2): 142-146 https://doi. org/10.1111/j.1399-3054.1948.tb07118.x 
Luwe MW, Takahama U, Heber U. 1993. Role of ascorbate in detoxifying ozone in the apoplast of spinach (Spinacia oleracea L.) leaves. Plant physiol. 101(3):969-976. https://doi.org/10.1104/pp.101.3.969 PMid:12231749 PMCid:PMC158714

Lyons T, Ollerenshaw JH , Barnes JD. 1999. Impacts of ozone on Plantago major: apoplastic and symplastic antioxidant status. New Phytol. 141(2): 253-263 https:// doi.org/10.1046/j.1469-8137.1999.00338.x

Maketon M, Apisitsantikul J, Siriraweekul C. 2008. Greenhouse evaluation of Bacillus subtilis AP-01 and Trichoderma harzianum AP-001 in controlling tobacco diseases. Braz J Microbiol. 39(2): 296-300 https://doi.org/10.1590/S1517-83822008000200018 PMid:24031219 PMCid:PMC3768408

Mendes R, Pizzirani-Kleiner AA, Araujo WL, Raaijmakers JM. 2007. Diversity of cultivated endophytic bacteria from sugarcane: genetic and biochemical characterization of Burkholderia cepacia complex isolates. Appl Environ Microbiol. 73(22): 7259-7267 https://doi.org/10.1128/ AEM.01222-07 PMid:17905875 PMCid:PMC2168197

Misaghi IJ, Donndelinger,CR. 1990. Endophytic bacteria in symptom-free cotton plants. Phytopathology 80(9): 808-811. https://doi.org/10.1094/Phyto-80-808

Nabti EH, Mokrane N, Ghoul M, Manyani H, Dary M, Megias MG. 2013. Isolation and characterization of two halophilic Bacillus (Bacillus licheniformis and Bacillus sp.) with antifungal activity. $J$ Ecol Health Environ. 1: 13-17 https://doi.org/10.12785/jehe/010102

Nouchi I, Hayashi K, Hiradate S, Ishikawa S, Fukuoka M, Chen CP, Kobayashi K. 2012. Overcoming the difficulties in collecting apoplastic fluid from rice leaves by the infiltration-centrifugation method. Plant Cell Physiol. 53(9):1659-1668. https://doi.org/10.1093/pcp/ pcs102 PMid:22813544

Prameela TP. 2016. Studies on biovar specific diagnostics for Ralstonia solanacearum Yabuuchi (Smith) infecting ginger (Zingiber officinale Rosc.) and evaluation of apoplastic microbes for biocontrol. Ph.D. Thesis. Submitted to Mangalore University, Karnataka.

Ramesh R, Joshi AA. Ghanekar MP. 2009. Pseudomonads: major antagonistic endophytic bacteria to suppress bacterial wilt pathogen, Ralstonia solanacearum in the eggplant (Solanum melongena L.). World J Microbiol Biotechnol. 25(1): 47-55 https://doi.org/10.1007/ s11274-008-9859-3
Roberts PD, Momol MT, Ritchie L, Olson SM, Jones JB, Balogh B. 2008. Evaluation of spray programs containing famoxadone plus cymoxanil, acibenzolarS-methyl, and Bacillus subtilis compared to copper sprays for management of bacterial spot on tomato. Crop Prot. 27(12): 1519-1526 https://doi.org/10.1016/j. cropro.2008.06.007

Rudrappa T, Biedrzycki ML, Kunjeti SG, Donofrio NM, Czymmek KJ, Paul WP, Bais HP. 2010. The rhizobacterial elicitor acetoin induces systemic resistance in Arabidopsis thaliana. Commun Integr Biol. 3(2): 130-138 https://doi.org/10.4161/cib.3.2.10584 PMid:20585504 PMCid:PMC2889968

Saddler GS. 2005. Management of bacterial wilt disease. pp. 121-132. In: Allen C, Prior P, Hayward AC (Eds.). Bacterial wilt disease and the Ralstonia solanacearum species complex. APS press.

Sarwar M, Kremer RJ. 1995. Determination of bacterially derived auxins using a microplate method. Lett Appl Microbiol. 20(5): 282-285. https://doi.org/10.1111/ j.1472-765X.1995.tb00446.x

Schwyn B, Neilands JB. 1987. Universal chemical assay for the detection and determination of siderophores. Anal Biochem. 160(1): 47-56. https://doi.org/10.1016/00032697(87)90612-9

Upreti R, Thomas P. 2015. Root-associated bacterial endophytes from Ralstonia solanacearum resistant and susceptible tomato cultivars and their pathogen antagonistic effects. Front Microbiol. 6: 255. https:// doi.org/10.3389/fmicb.2015.00255 PMid:25926818 PMCid:PMC4396348

Van Peer R, Niemann GJ, Schippers B. 1991. Induced resistance and phytoalexin accumulation in biological control of Fusarium wilt of carnation by Pseudomonas sp. strain WCS417r. Phytopathology 81(7): 728-734. https://doi.org/10.1094/Phyto-81-728

Vermelho AB, Meirelles MNL, Lopes A, Petinate SDG, Chaia AA, Branquinha MH. 1996. Detection of extracellular proteases from microorganisms on agar plates. Mem Inst Oswaldo Cruz. 91(6): 755-760. https://doi.org/10.1590/ S0074-02761996000600020 PMid:9283660

Wang XB, Luo YM, Liu WX, Li ZG. 2011. Identification, antimicrobial activity and field control efficacy of an endophytic bacteria strain against peanut bacterial wilt. Chin J Biol Control 27(1): 88-92. 
Yamada T, Kawasaki T, Nagata S, Fujiwara A, Usami S, Fujie M. 2007. New bacteriophages that infect the phytopathogen Ralstonia solanacearum. Microbiology 153 (8): 2630-2639. https://doi.org/10.1099/ mic.0.2006/001453-0 PMid:17660427

Yoon JH, Kim IG, Kang KH, Oh TK, Park YH. 2003. Bacillus marisflavi sp. nov. and Bacillus aquimaris sp. nov., isolated from sea water of a tidal flat of the Yellow Sea in Korea. Int J Syst Evol Microbiol. 153(8): 2630-2639. https://doi.org/10.1099/ijs.0.02365-0
Zinniel DK, Lambrecht P, Harris NB, Feng Z, Kuczmarski D, Higley P, Ishimaru CA, Arunakumari A, Barletta RG, Vidaver AK. 2002. Isolation and characterization of endophytic colonizing bacteria from agronomic crops and prairie plants. Appl Environ Microbiol. 68(5): 2198-2208. https://doi.org/10.1128/AEM.68.5.21982208.2002 PMid:11976089 PMCid:PMC127535 